\title{
Palladium-Catalyzed Oxidative Synthesis of Unsymmetrical Azophenols
}

Thi Hong Long Nguyen, ${ }^{\ddagger}$ Nicolas Gigant, ${ }^{\ddagger}$ Sandrine Delarue-Cochin, and Delphine Joseph*

BioCIS, Université Paris-Sud, CNRS, Université Paris-Saclay, F-92296 Châtenay-Malabry, France.

delphine.joseph@u-psud.fr

\section{Table of contents}

1. Optimization of the Reaction Conditions by in situ Generation of PIFA 2

2. Copies of ${ }^{1} \mathrm{H},{ }^{13} \mathrm{C}$ and ${ }^{19} \mathrm{~F}$ NMR spectra........ 3 


\section{Optimization of the Reaction Conditions by in situ Generation of PIFA}

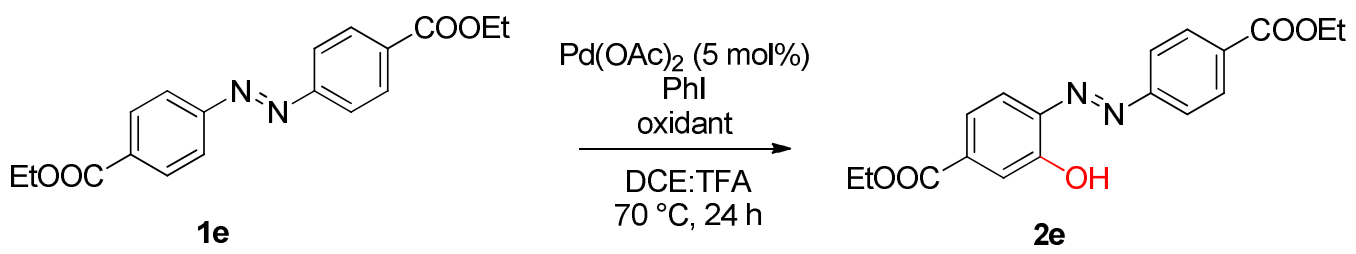

\begin{tabular}{lllll}
\hline entry $^{\mathrm{a}}$ & PhI (mol\%) & Oxidant (equiv) & solvant & Yield (\%) $^{\mathrm{b}}$ \\
\hline 1 & 200 & Oxone (3) & DCE:TFA (1:1) & 51 \\
2 & 20 & Oxone (3) & DCE:TFA (1:1) & 47 \\
3 & 20 & Oxone (3) & DCE:TFA (8:2) & 25 \\
4 & 20 & Oxone (3) & DCE:TFA (3:7) & 43 \\
$\mathbf{5}$ & $\mathbf{2 0}$ & Oxone (2) & DCE:TFA (1:1) & $\mathbf{5 7}$ \\
6 & 20 & Oxone (1.5) & DCE:TFA (1:1) & 29 \\
7 & 10 & Oxone (2) & DCE:TFA (1:1) & 39 \\
8 & 0 & Oxone (2) & DCE:TFA (1:1) & 0 \\
9 & 20 & $\mathrm{~K}_{2} \mathrm{~S}_{2} \mathrm{O}_{8}(3)$ & DCE:TFA (1:1) & 0
\end{tabular}

${ }^{\mathrm{a}}$ Reaction conditions: $\mathbf{2 a}(0.20 \mathrm{mmol})$ under the appropriate reaction conditions $(\mathrm{c}=0.2$ mol.L $\left.{ }^{-1}\right) .{ }^{\mathrm{b}}$ Isolated yield. 


\section{Copies of ${ }^{1} \mathrm{H},{ }^{13} \mathrm{C}$ and ${ }^{19} \mathrm{~F}$ NMR spectra}

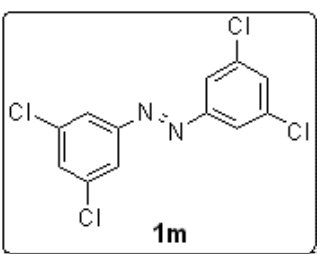

$\mathrm{CDCl}_{3}, 300 \mathrm{MHz}$

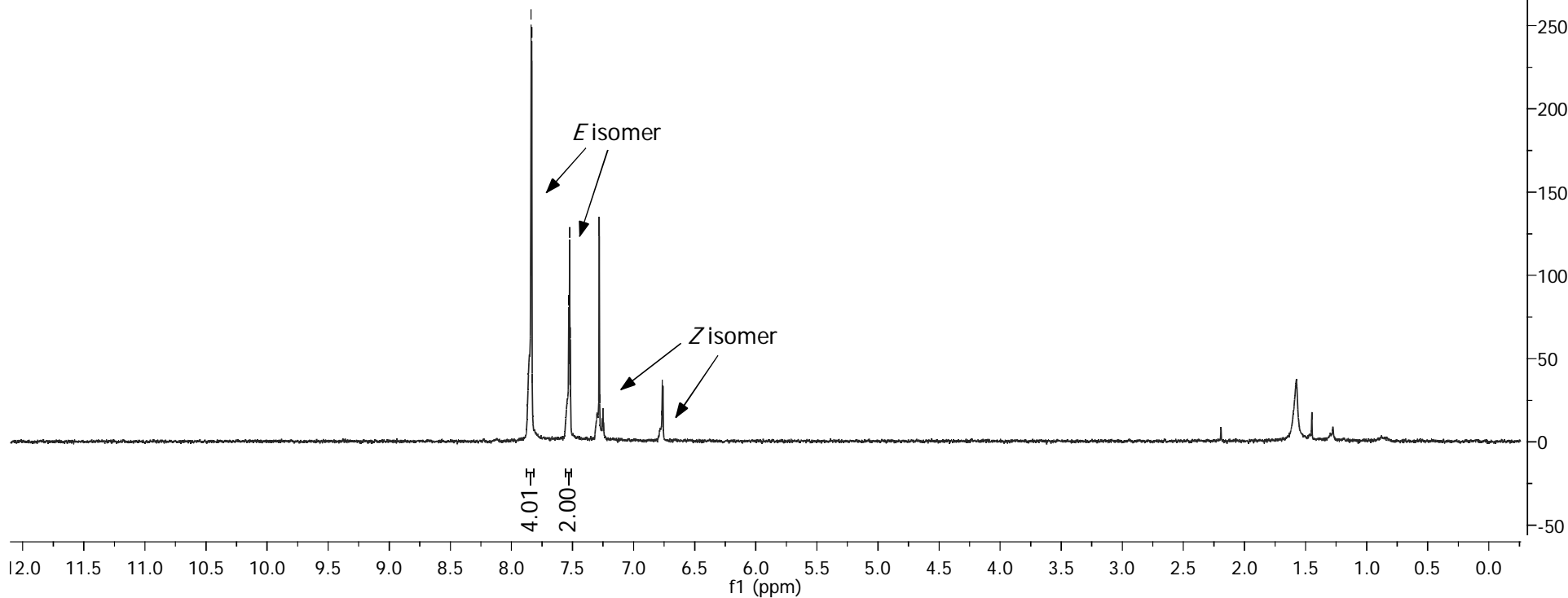

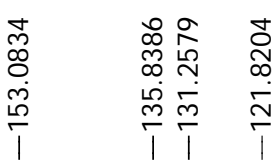

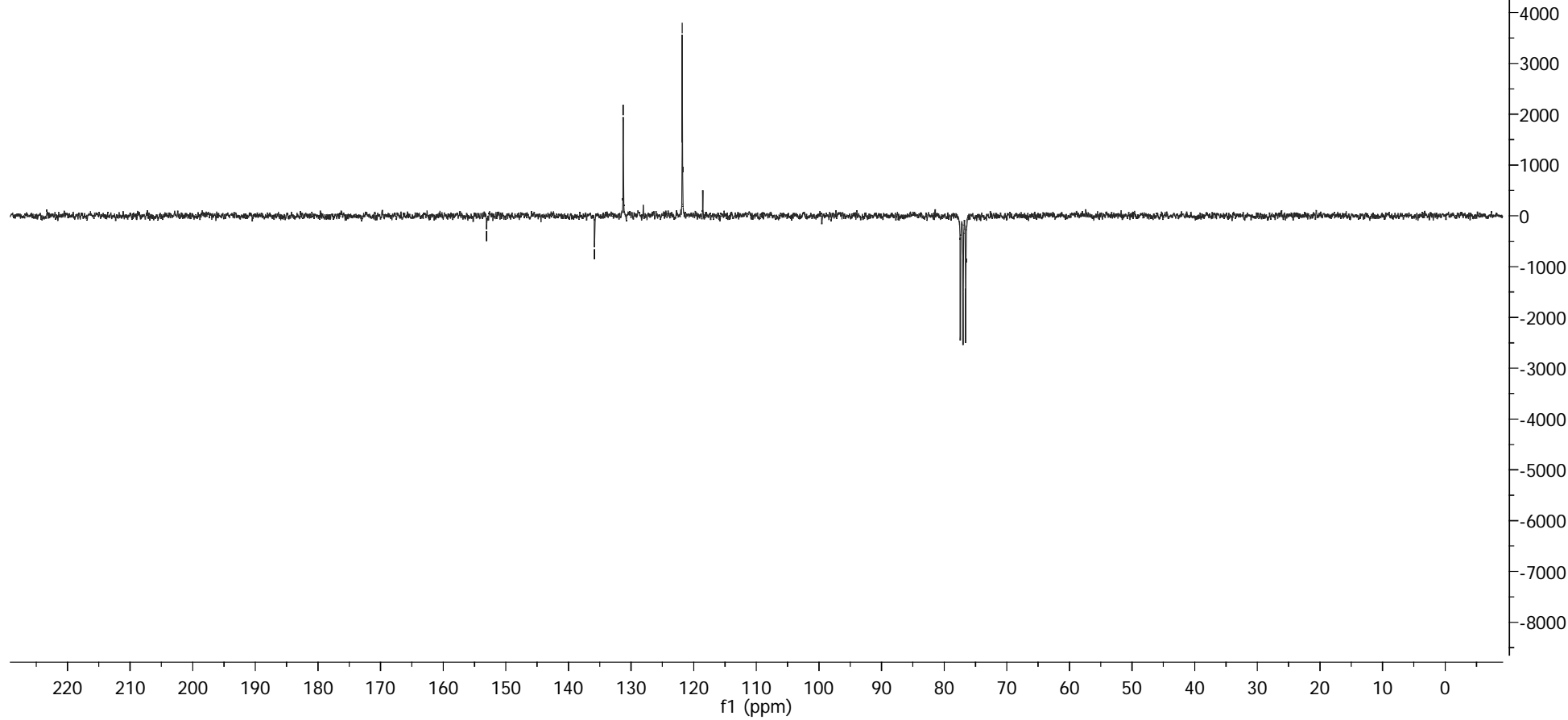




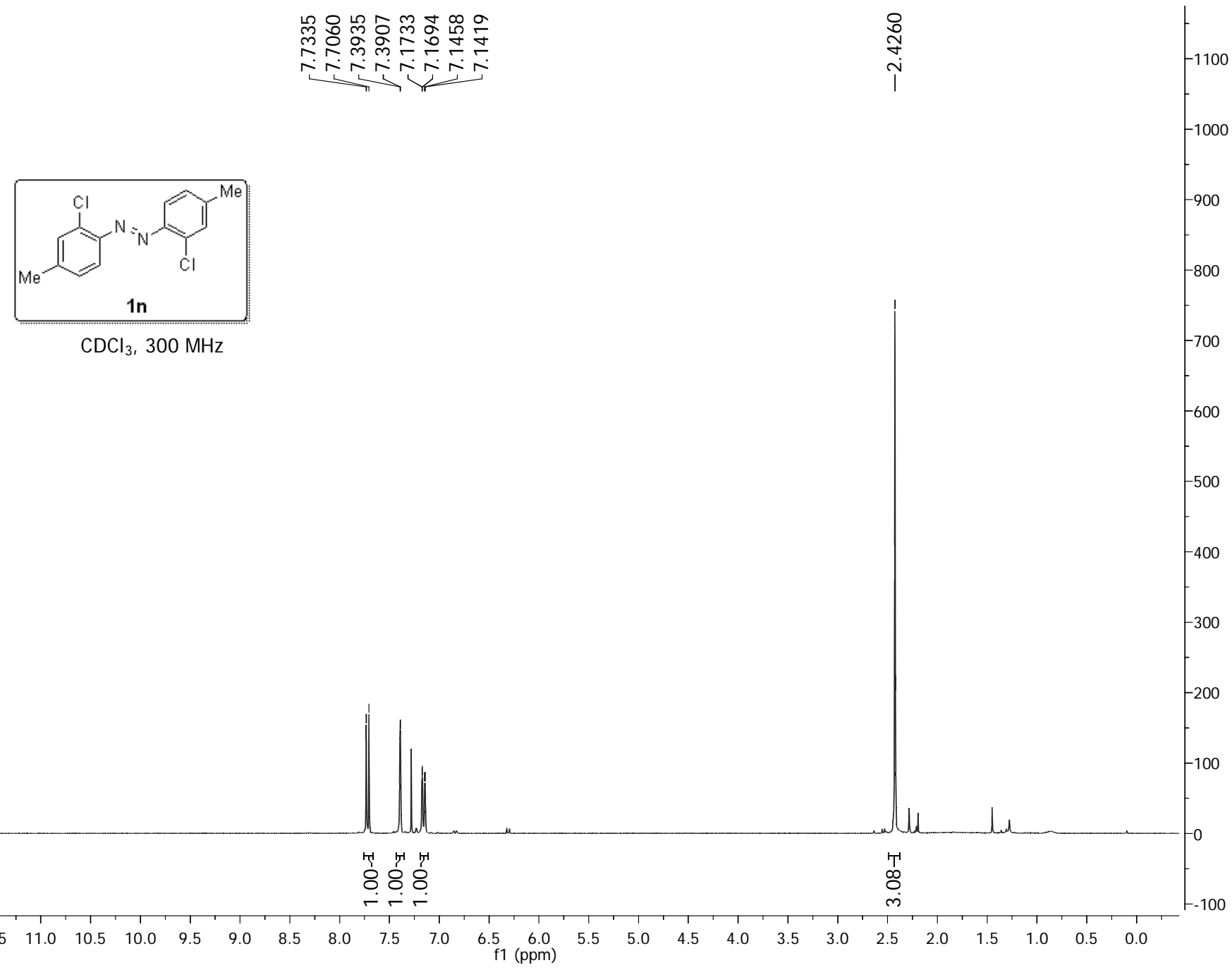

$\begin{array}{llllllllllllllllllllllllllllllll}12.5 & 12.0 & 11.5 & 11.0 & 10.5 & 10.0 & 9.5 & 9.0 & 8.5 & 8.0 & 7.5 & 7.0 & 6.5 & 6.0 & 5.5 & 5.0 & 4.5 & 4.0 & 3.5 & 3.0 & 2.5 & 2.0 & 1.5 & 1.0 & 0.5 & 0.0\end{array}$
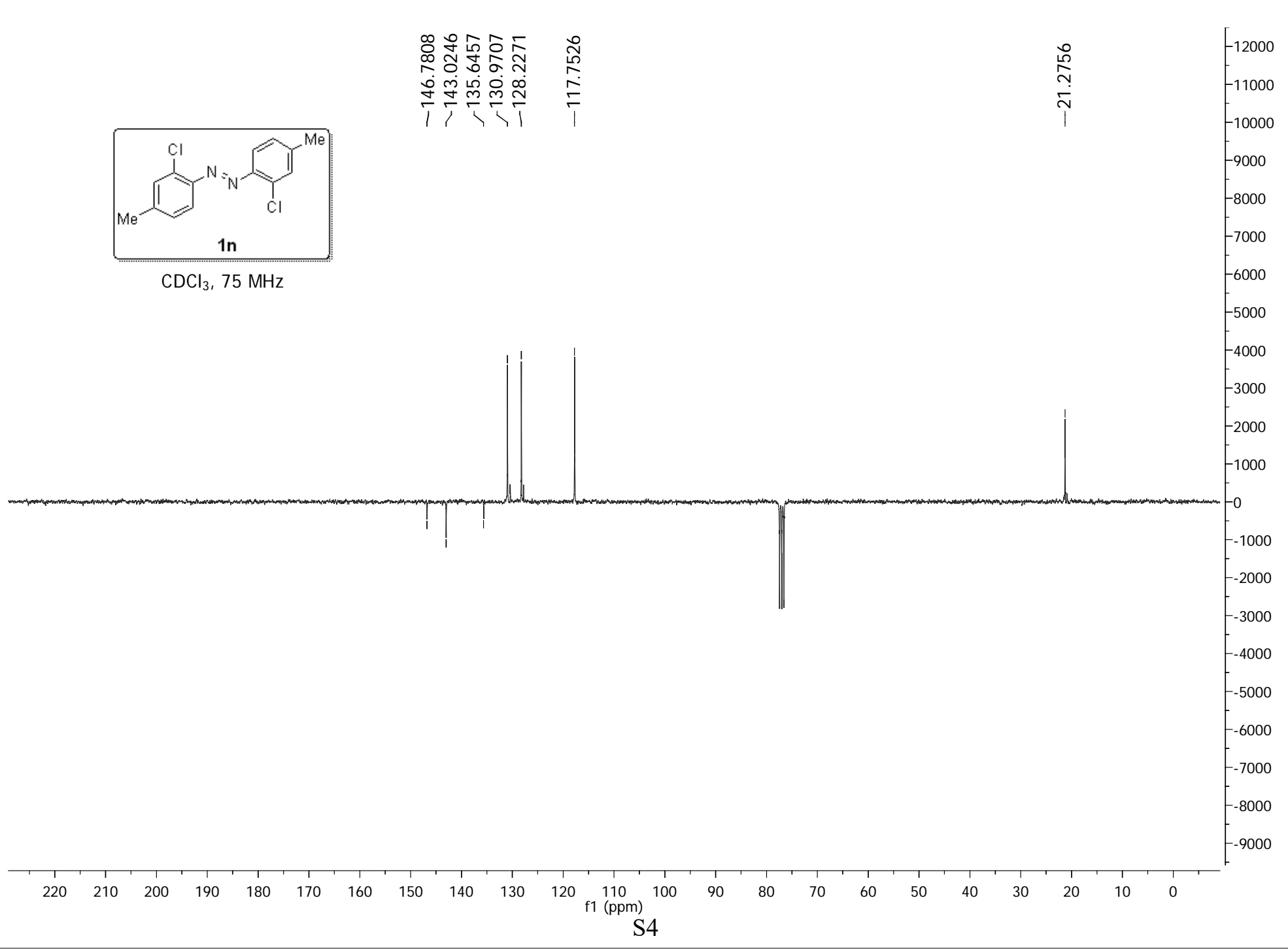


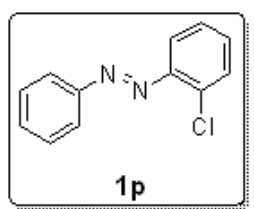

$\mathrm{CDCl}_{3}, 300 \mathrm{MHz}$

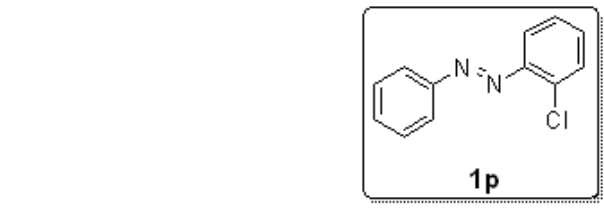

$\mathrm{CDCl}_{3}, 75 \mathrm{MHz}$

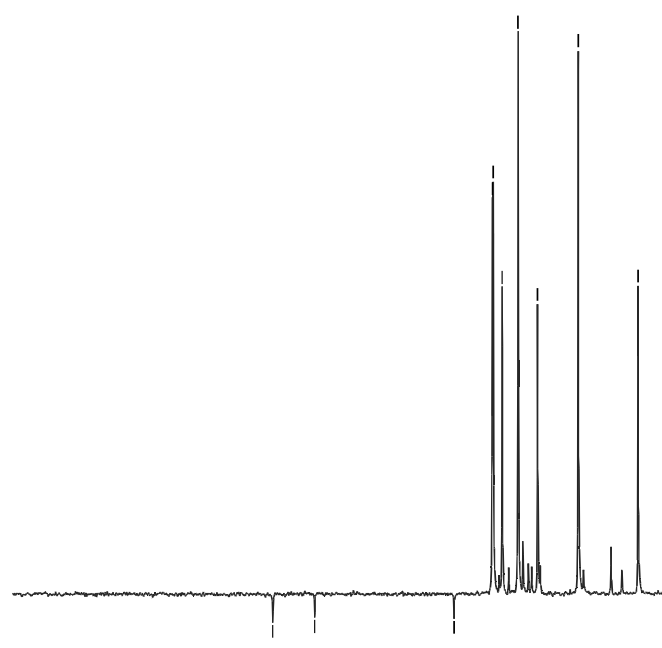




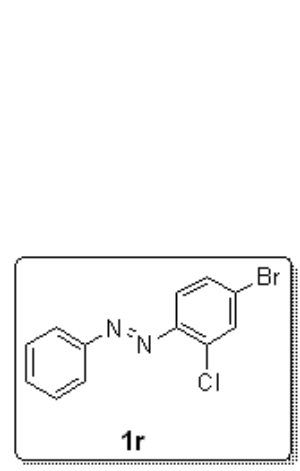

$\mathrm{CDCl}_{3}, 300 \mathrm{MHz}$

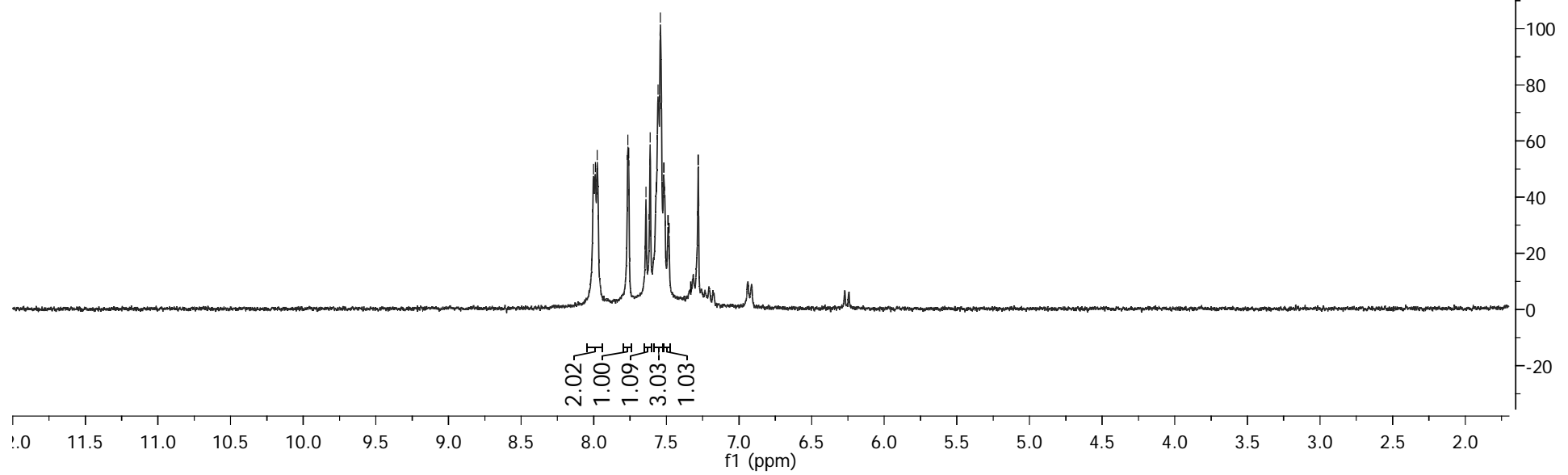

象 员

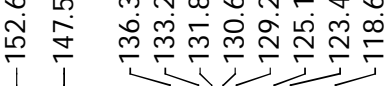
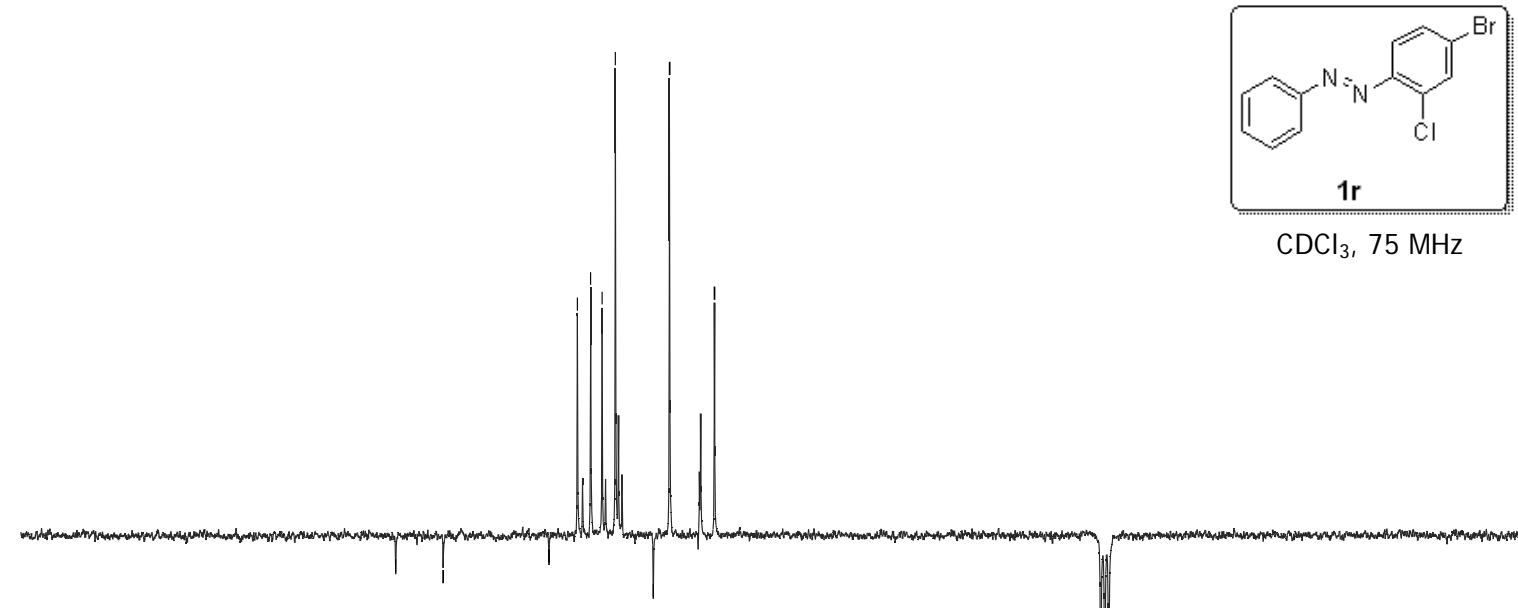

$\mathrm{CDCl}_{3}, 75 \mathrm{MHz}$

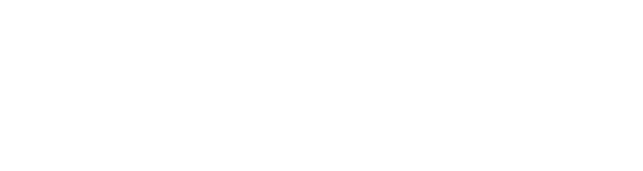

$-10000$

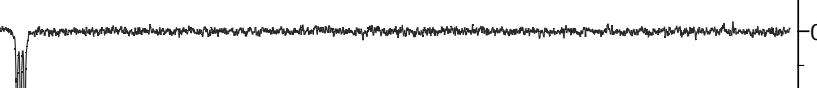




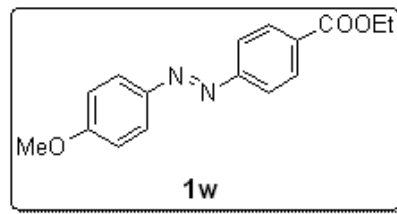

$\mathrm{CDCl}_{3}, 300 \mathrm{MHz}$

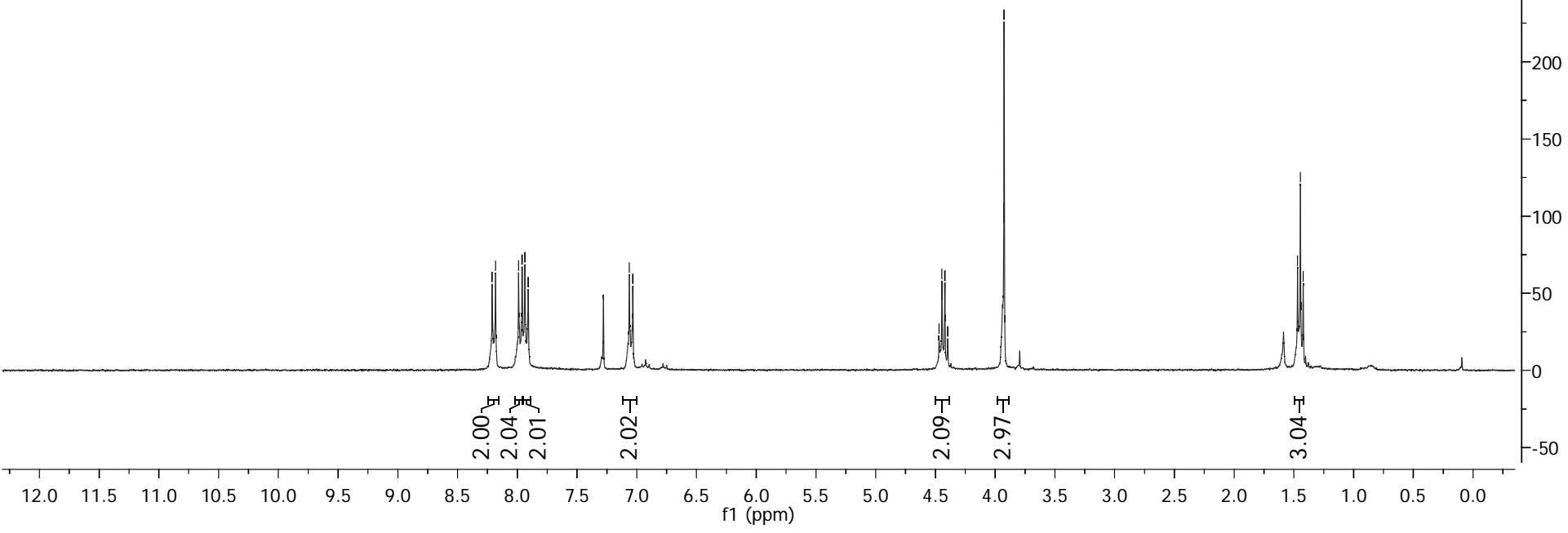

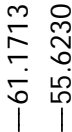

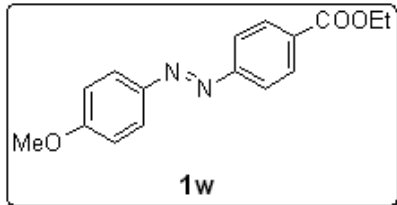

$\mathrm{CDCl}_{3}, 75 \mathrm{MHz}$

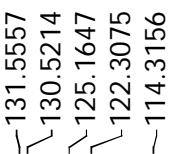

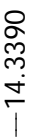

8000

000

000

000

000

3000 


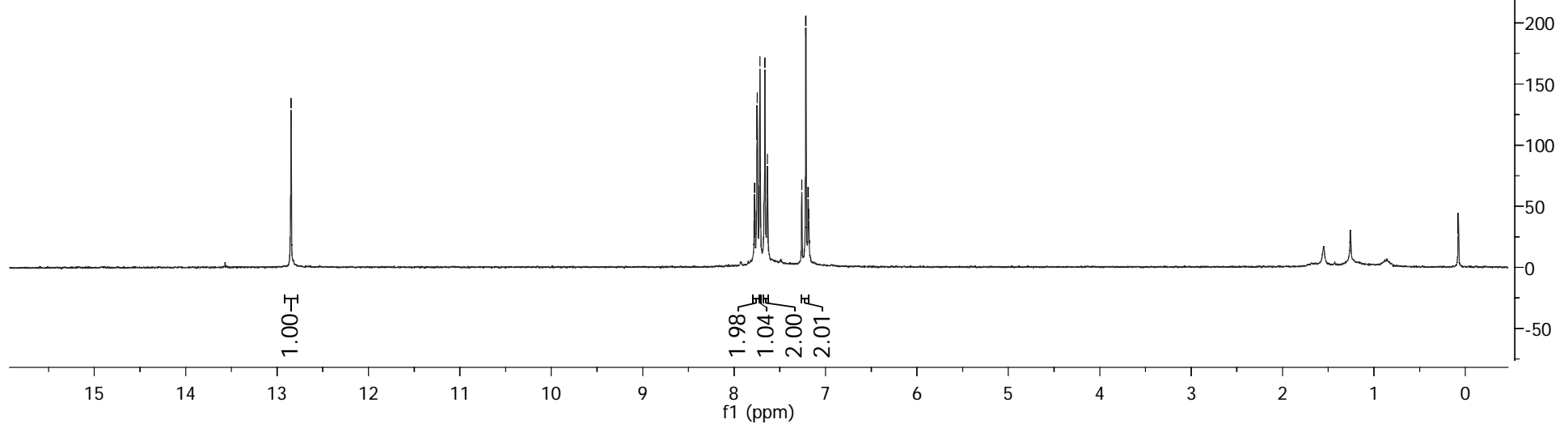

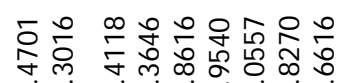

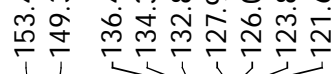

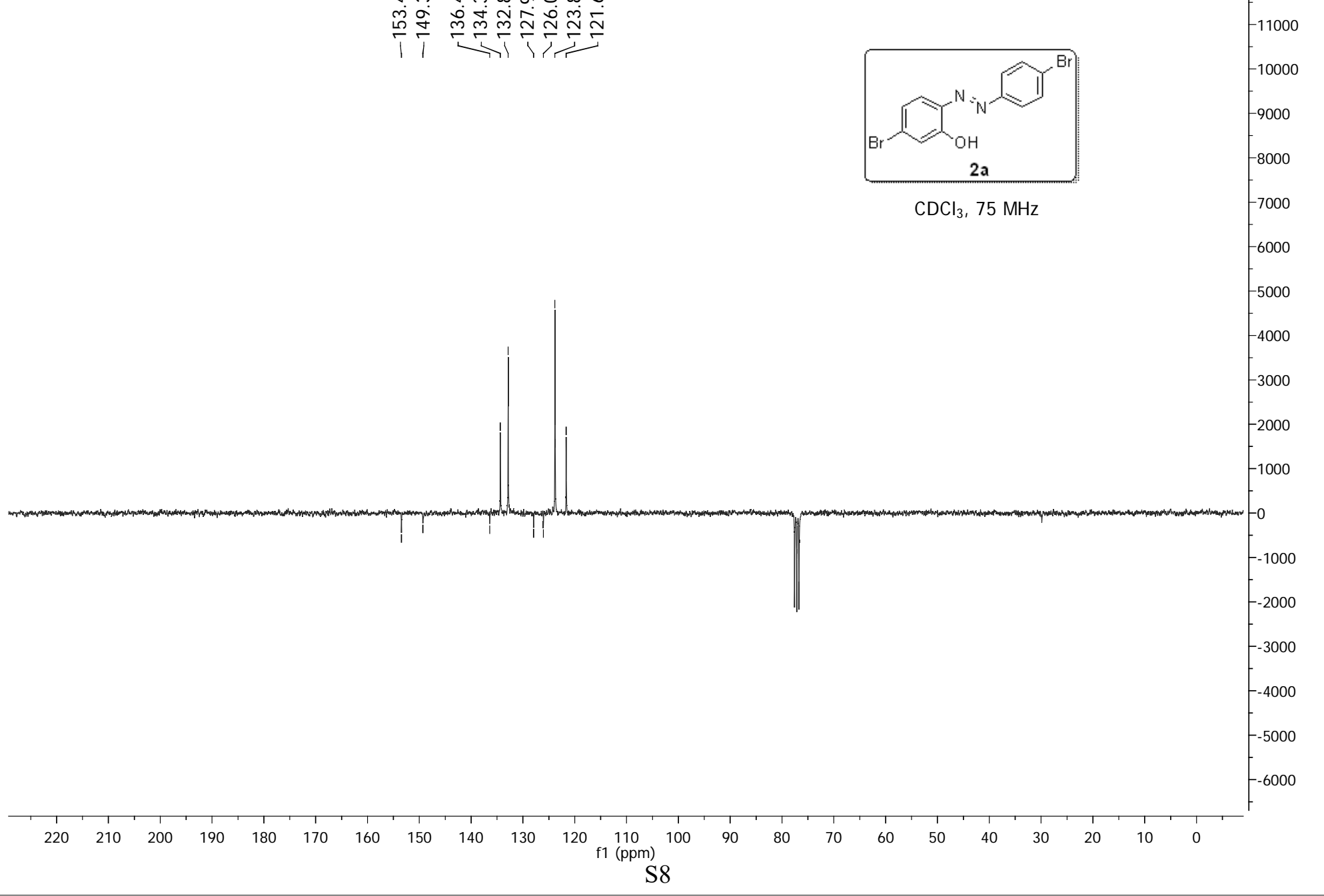




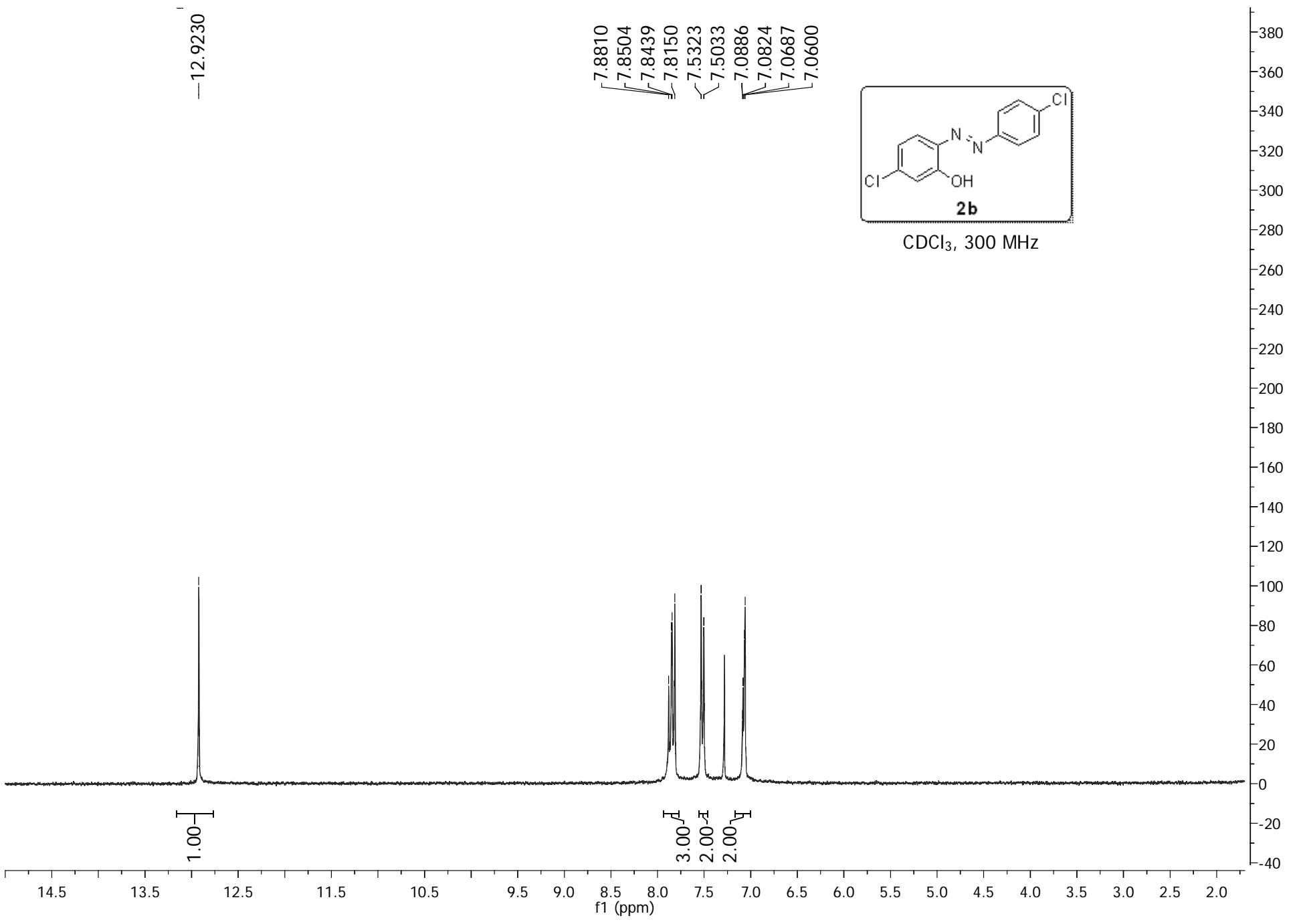

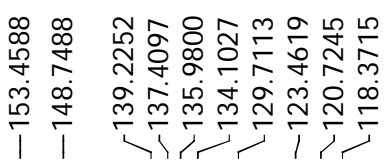

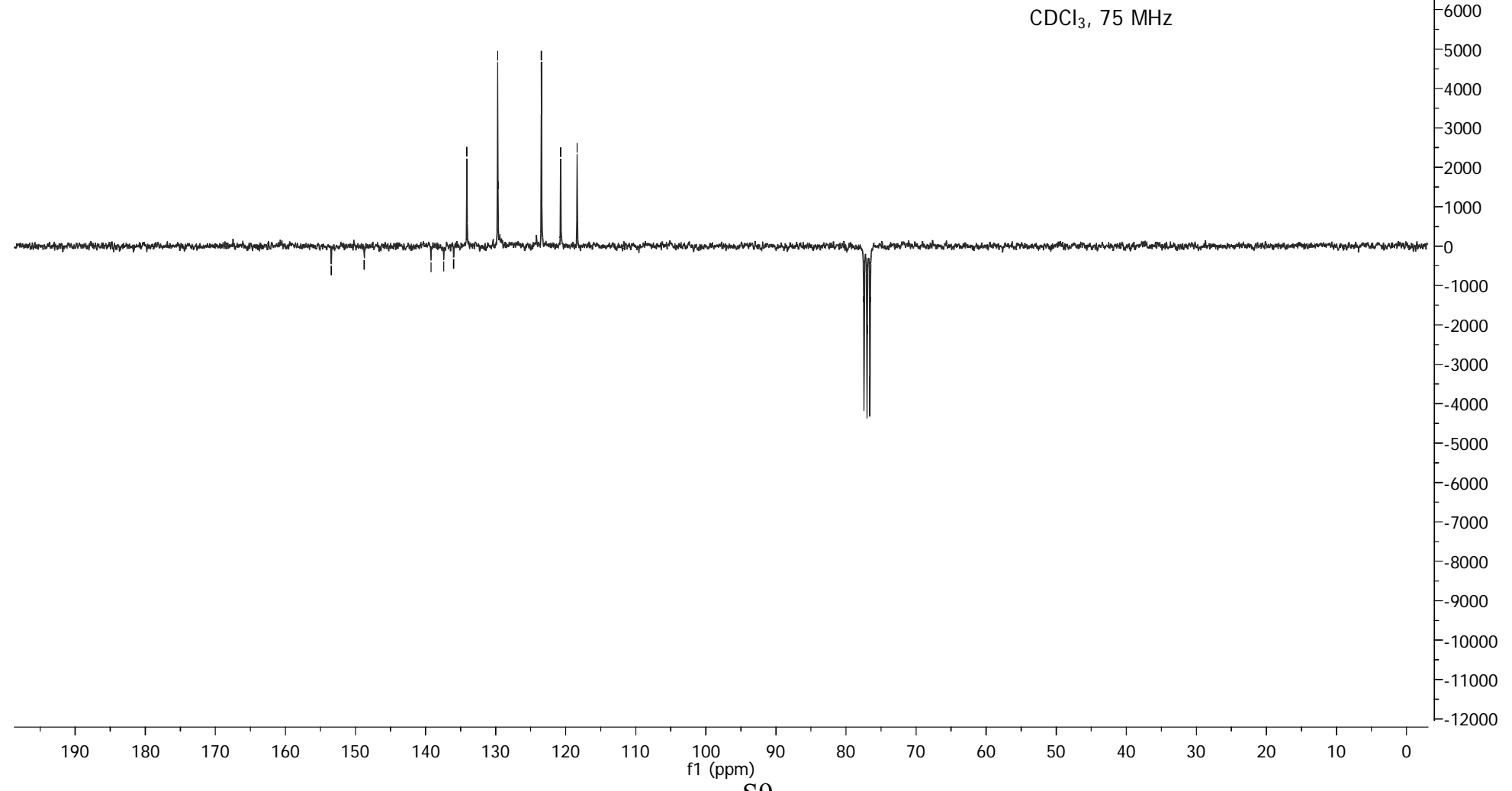




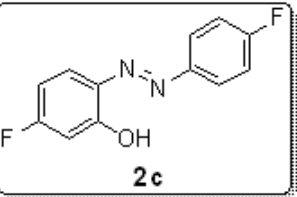

$\mathrm{CDCl}_{3}, 300 \mathrm{MHz}$

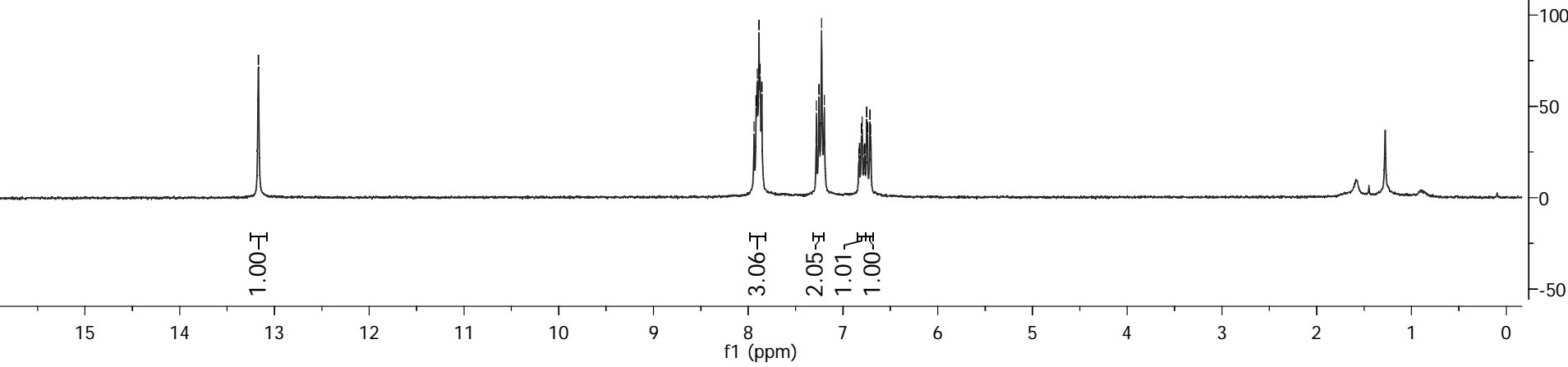

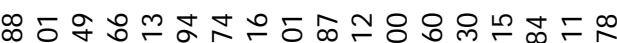

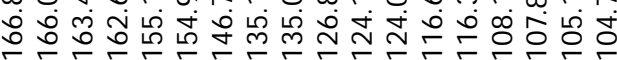

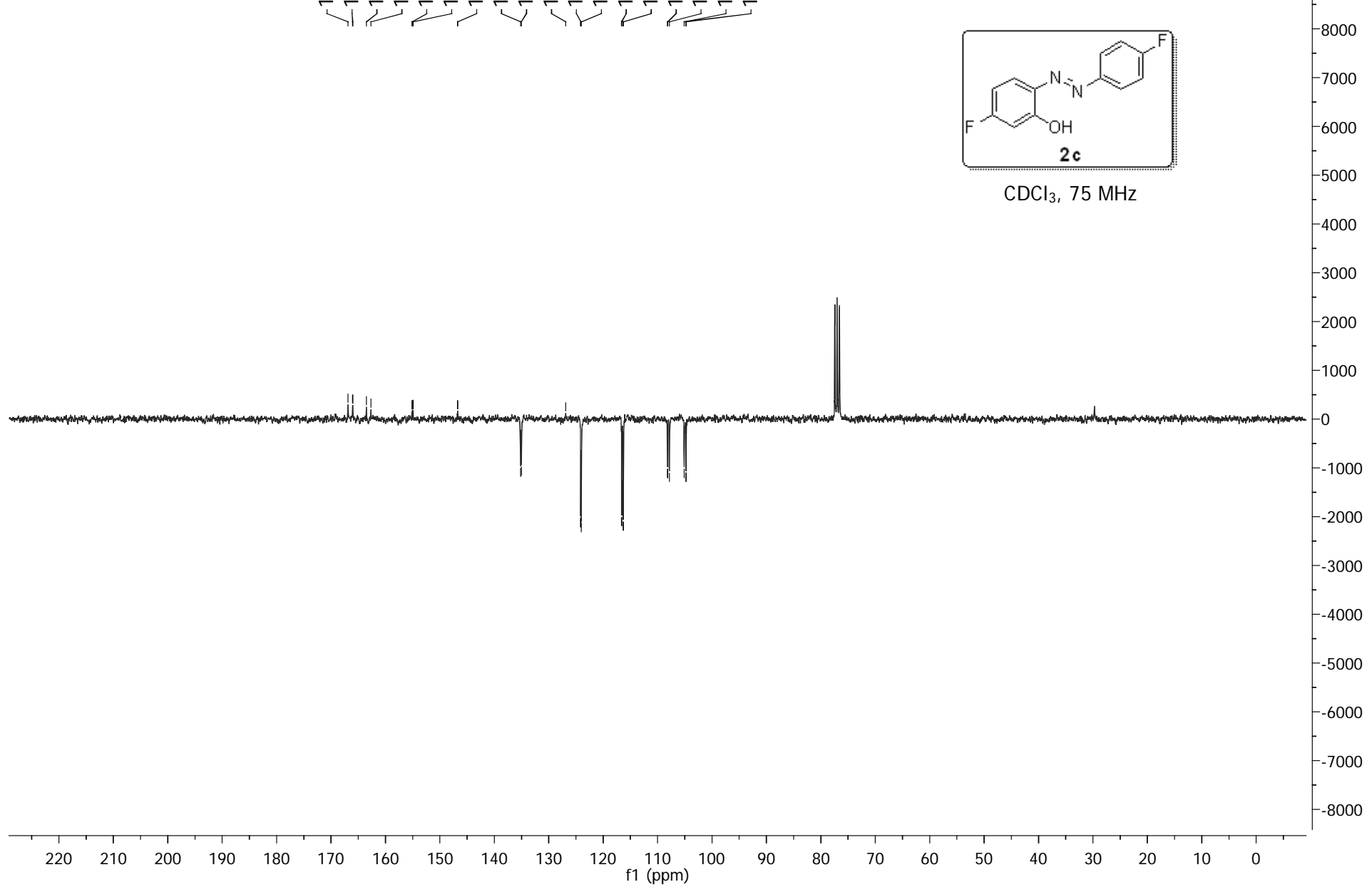




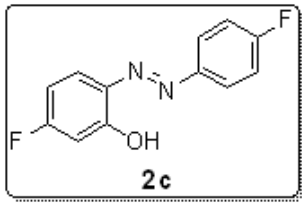

$\mathrm{CDCl}_{3}, 188 \mathrm{MHz}$

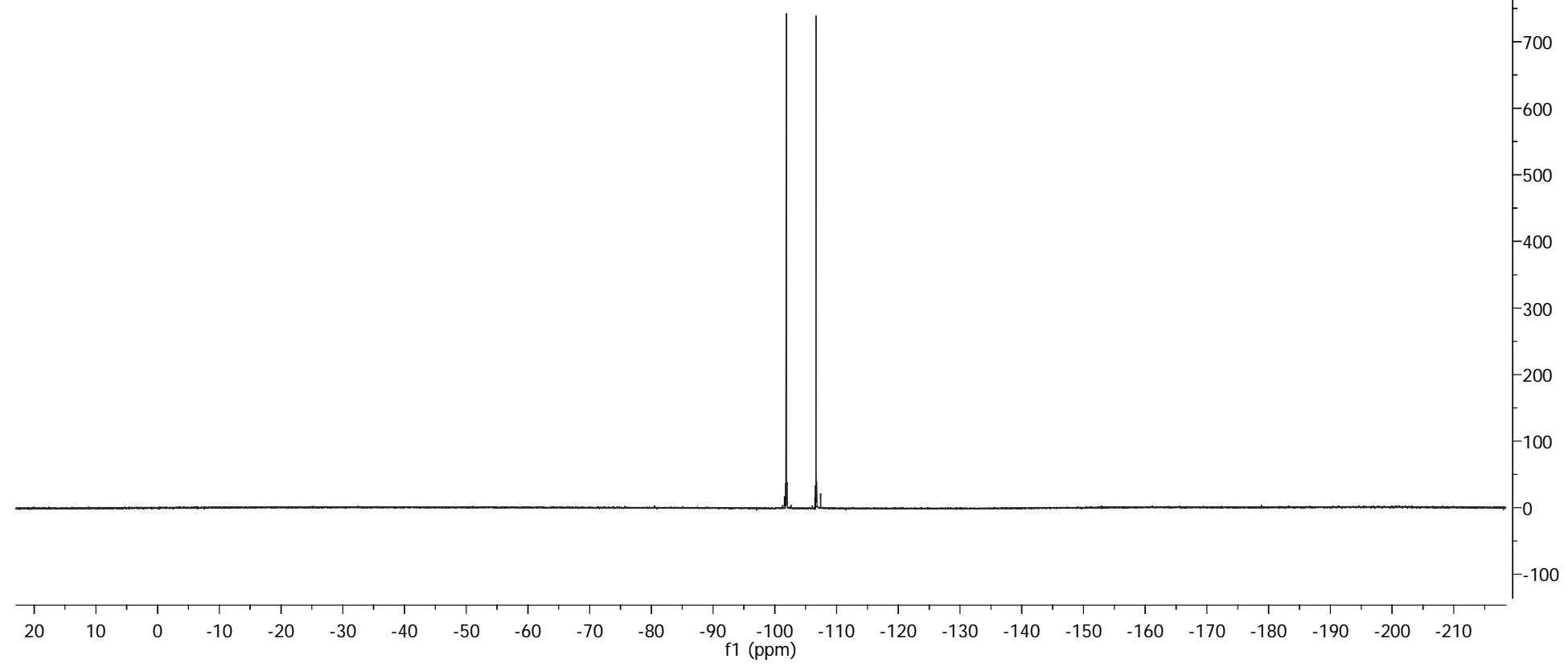

守臬 专

1.

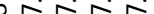

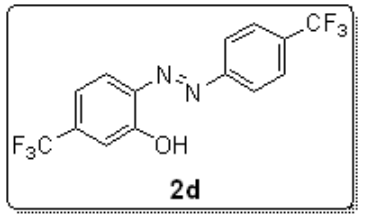

2d

$\mathrm{CDCl}_{3}, 300 \mathrm{MHz}$

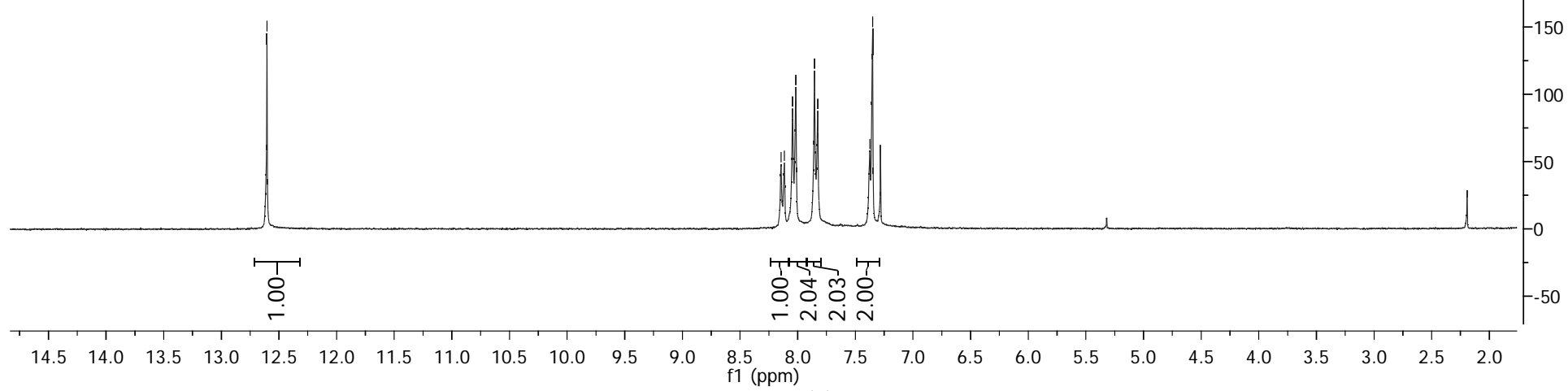




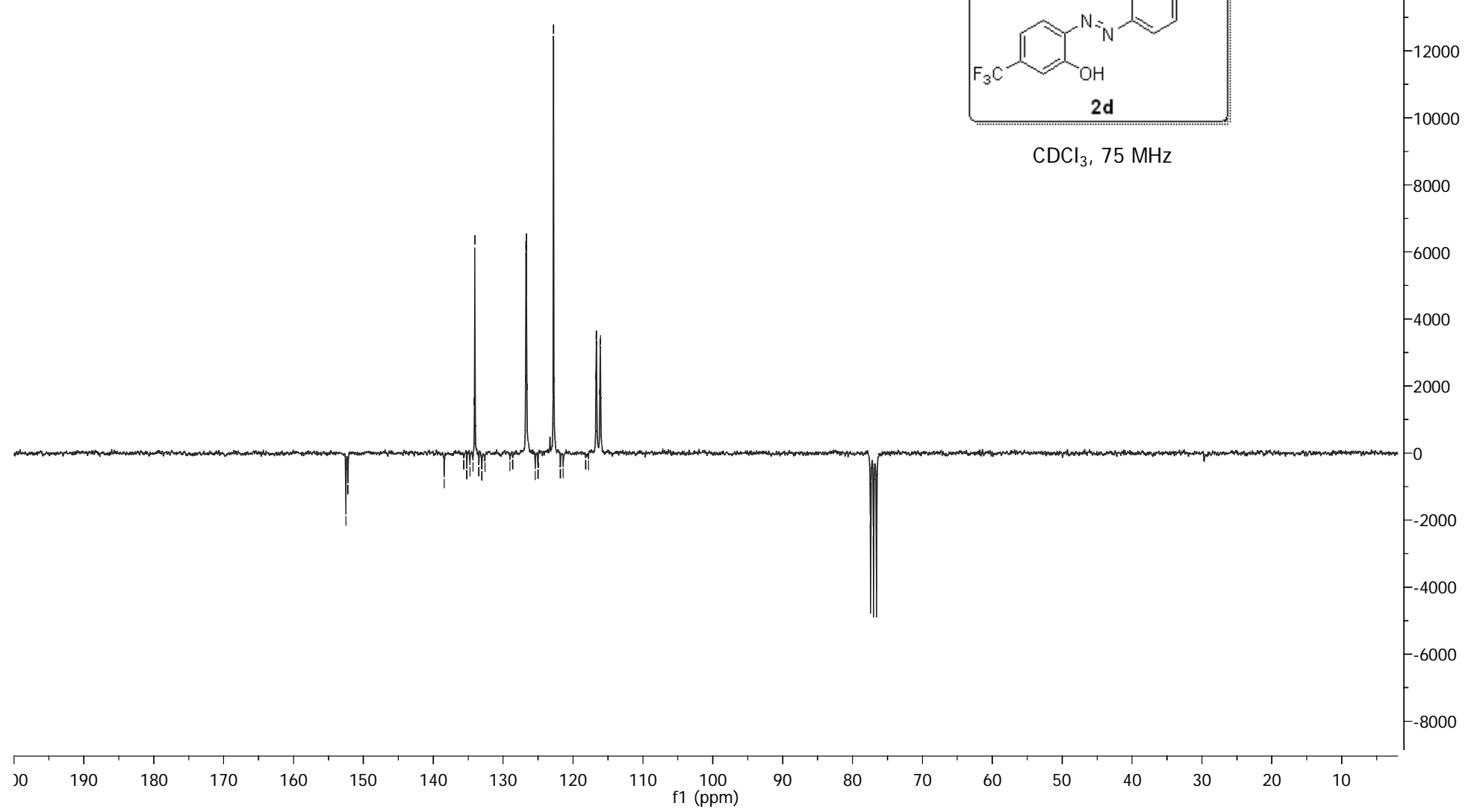

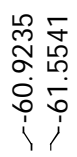

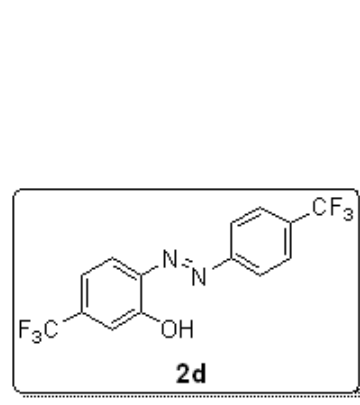

$\mathrm{CDCl}_{3}, 188 \mathrm{MHz}$

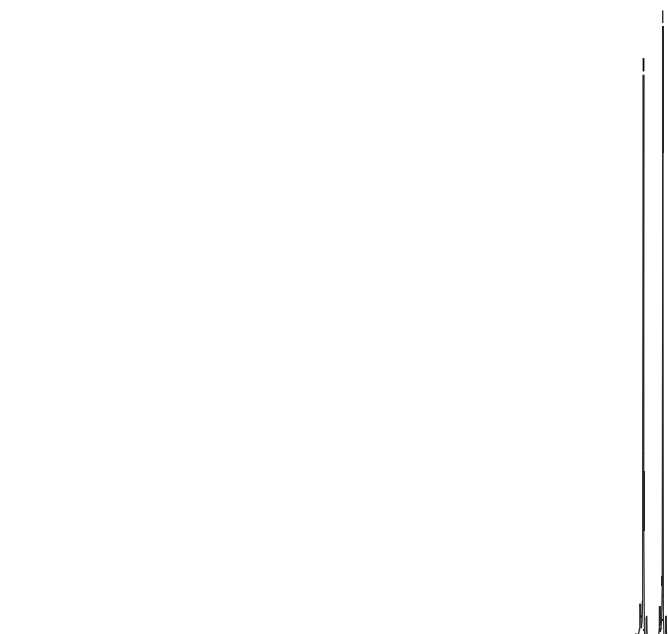

\begin{tabular}{|c|c|c|c|c|c|c|c|c|c|c|c|c|}
\hline 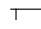 & 1 & 1 & 1 & 1 & 1 & 1 & 1 & 1 & 1 & 1 & 1 & $\Gamma^{1}$ \\
\hline 40 & -45 & -50 & -55 & -60 & -65 & $\begin{array}{c}-70 \\
\mathrm{f} 1(\mathrm{ppm})\end{array}$ & -75 & -80 & -85 & -90 & -95 & -100 \\
\hline
\end{tabular}




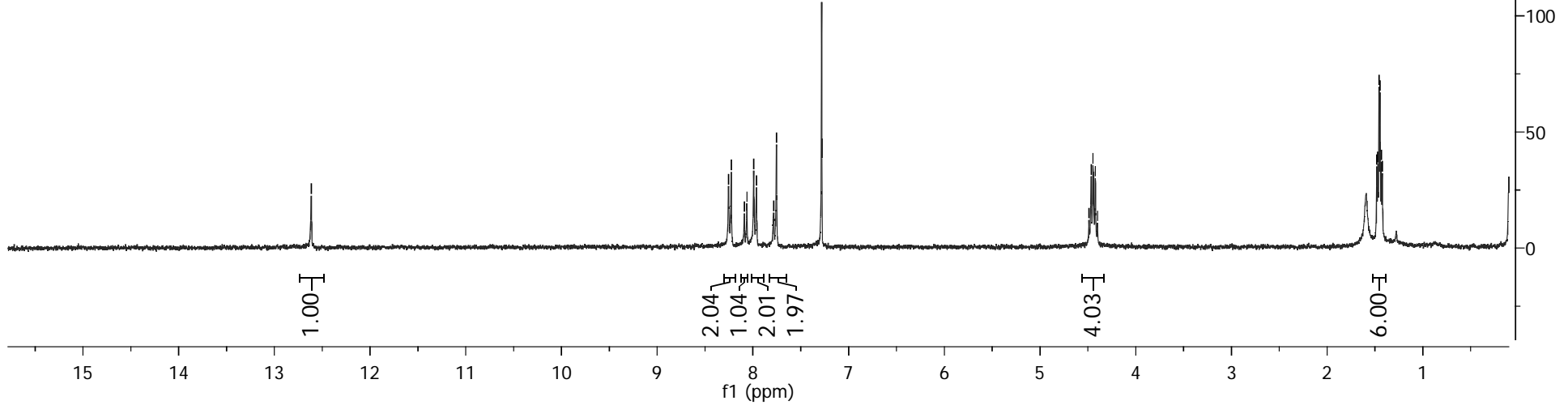

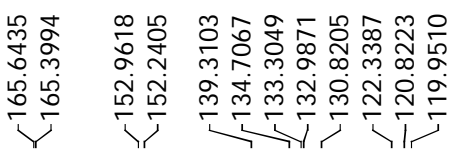

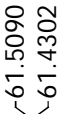

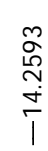

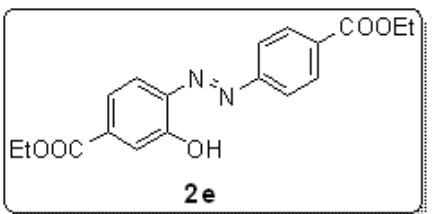

$\mathrm{CDCl}_{3}, 75 \mathrm{MHz}$
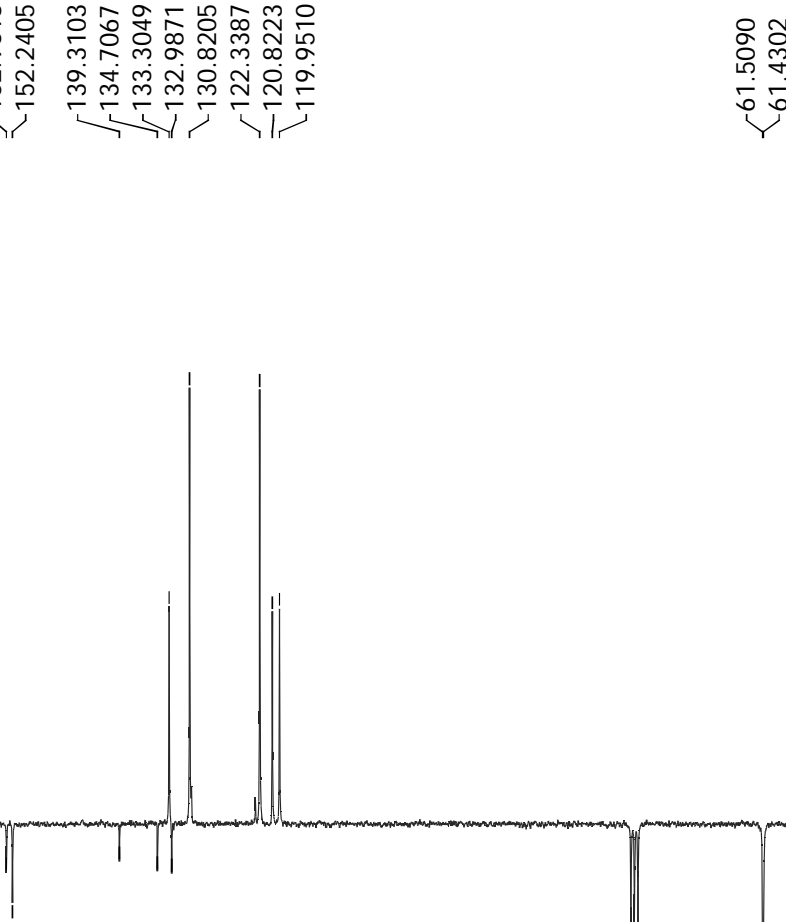


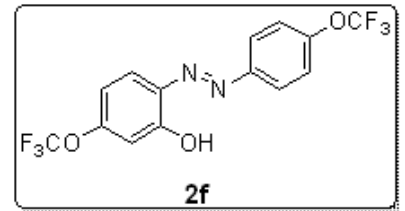

$\mathrm{CDCl}_{3}, 300 \mathrm{MHz}$

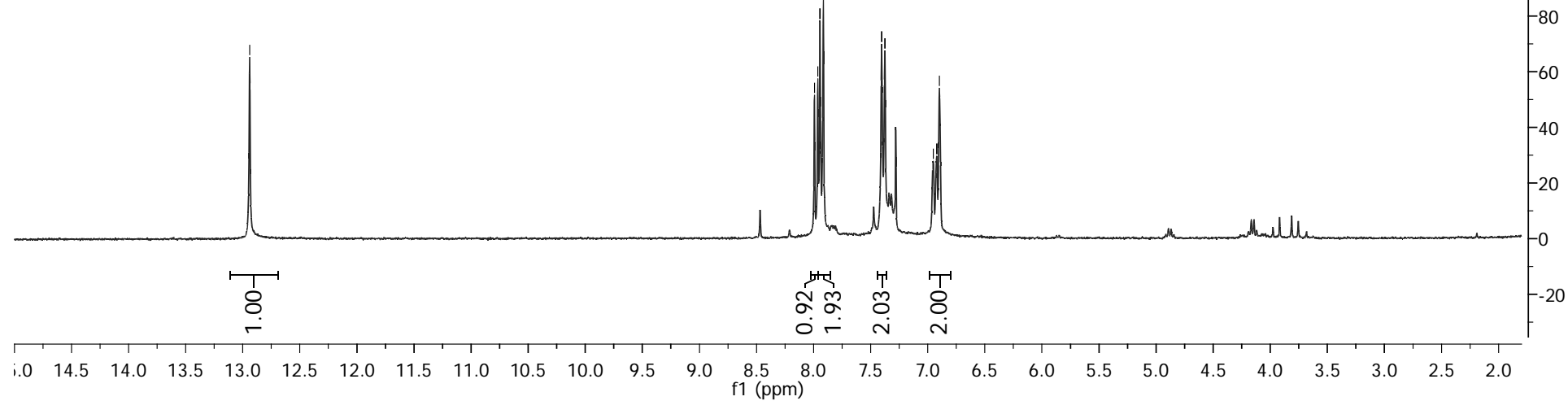

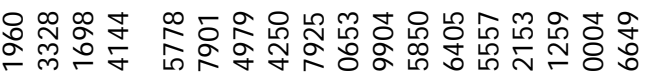

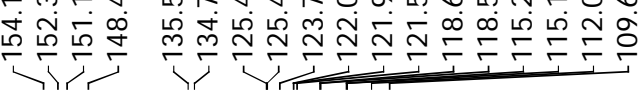

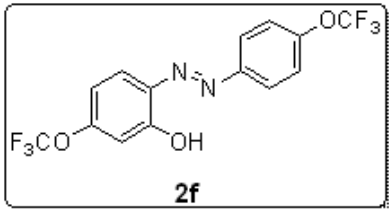

$\mathrm{CDCl}_{3}, 75 \mathrm{MHz}$

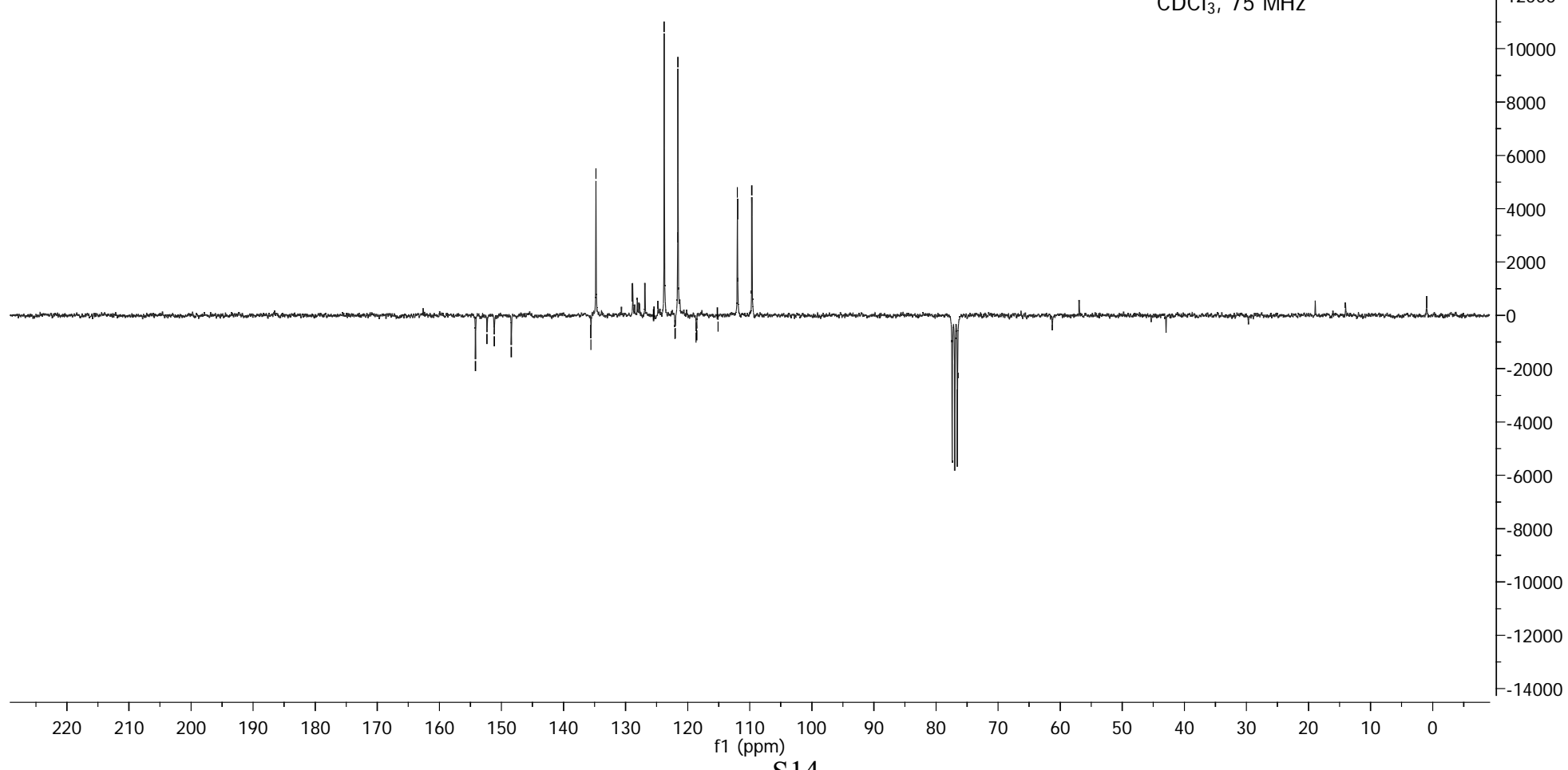




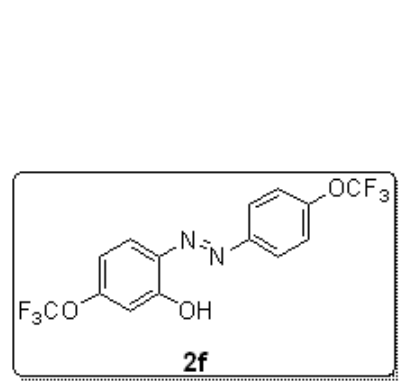

$\mathrm{CDCl}_{3}, 188 \mathrm{MHz}$

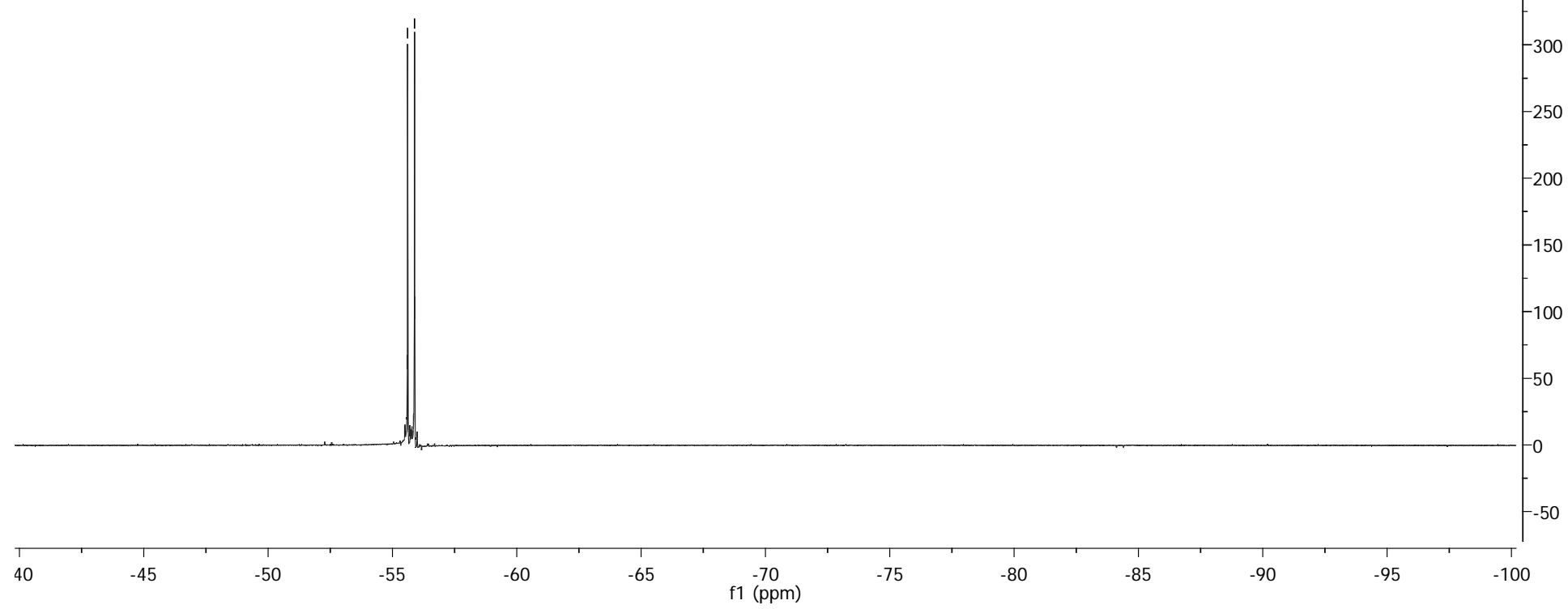

$\underset{\substack{\tilde{m} \\ \text { m }}}{\sim}$

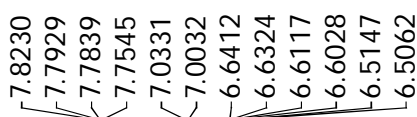

고요

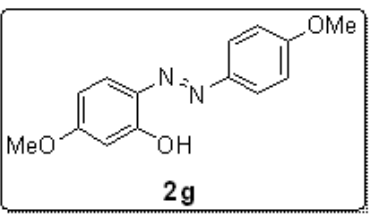

$\mathrm{CDCl}_{3}, 300 \mathrm{MHz}$

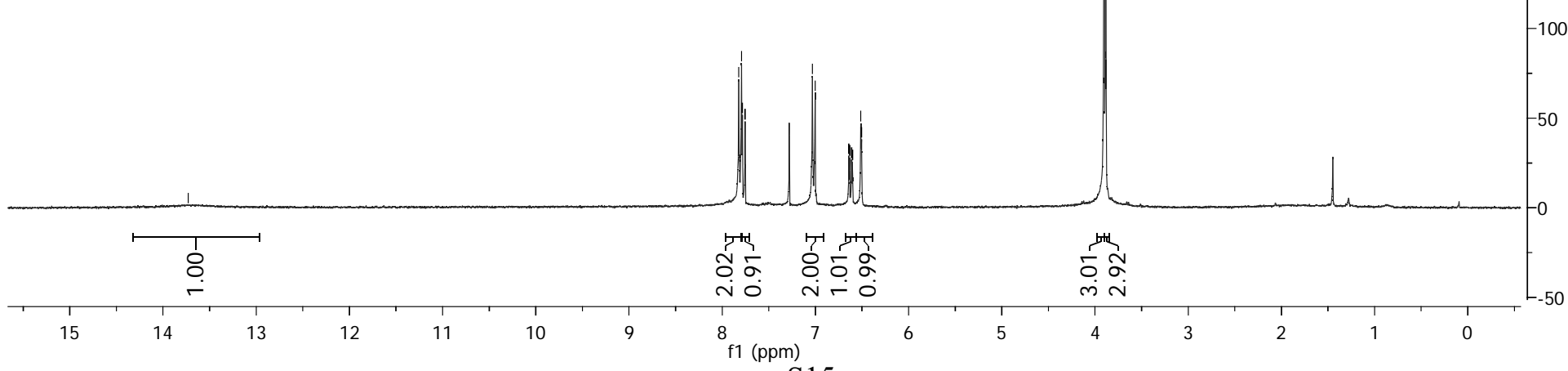




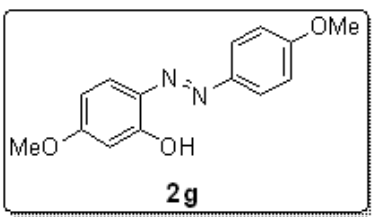

$2 \mathrm{~g}$

$\mathrm{CDCl}_{3}, 75 \mathrm{MHz}$

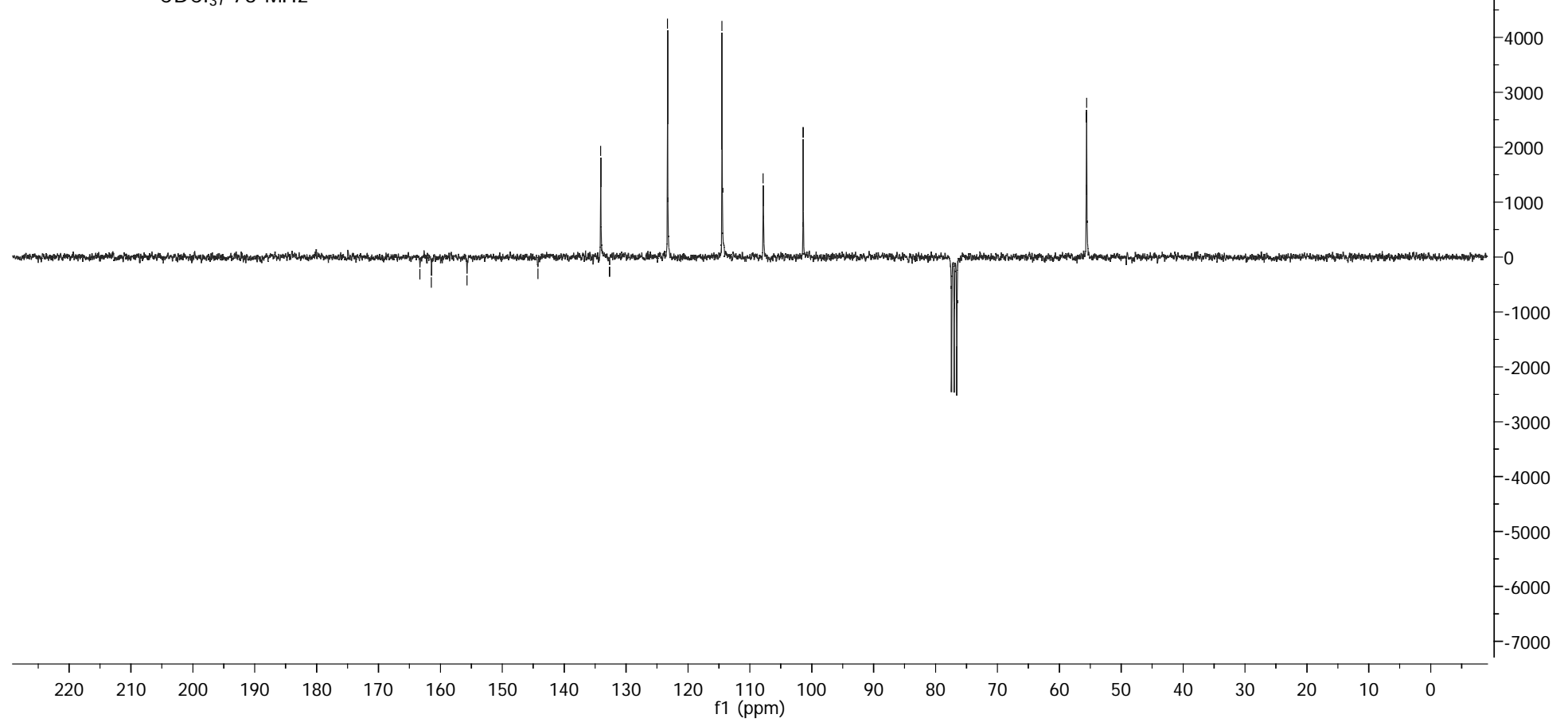

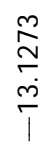

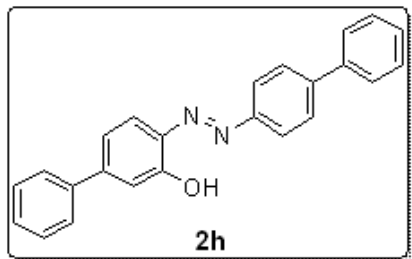

$\mathrm{CDCl}_{3}, 300 \mathrm{MHz}$

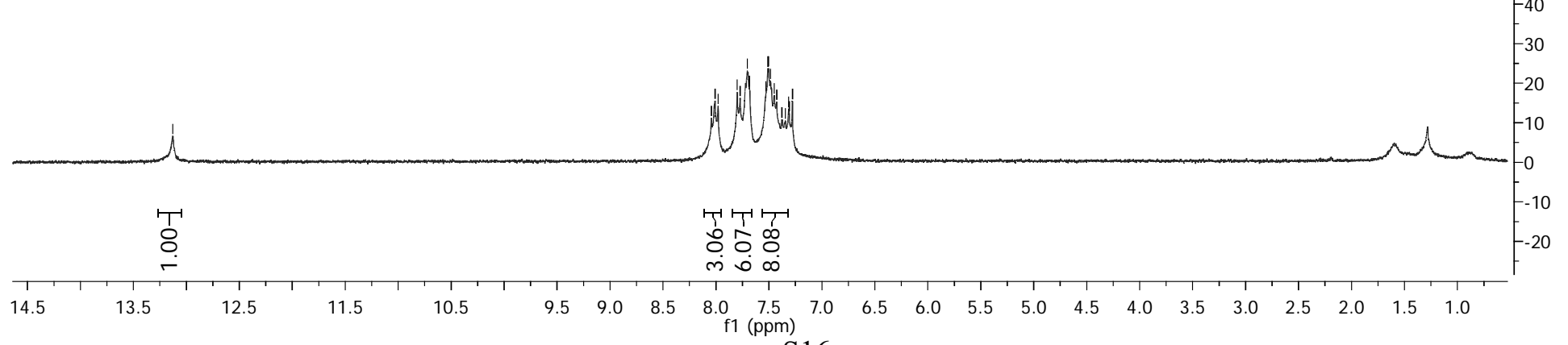




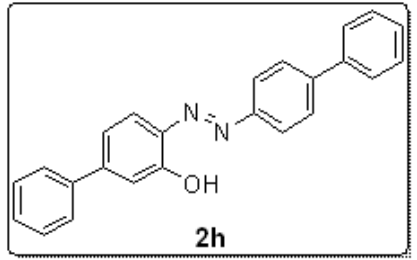

$2 \mathrm{~h}$

$\mathrm{CDCl}_{3}, 75 \mathrm{MHz}$

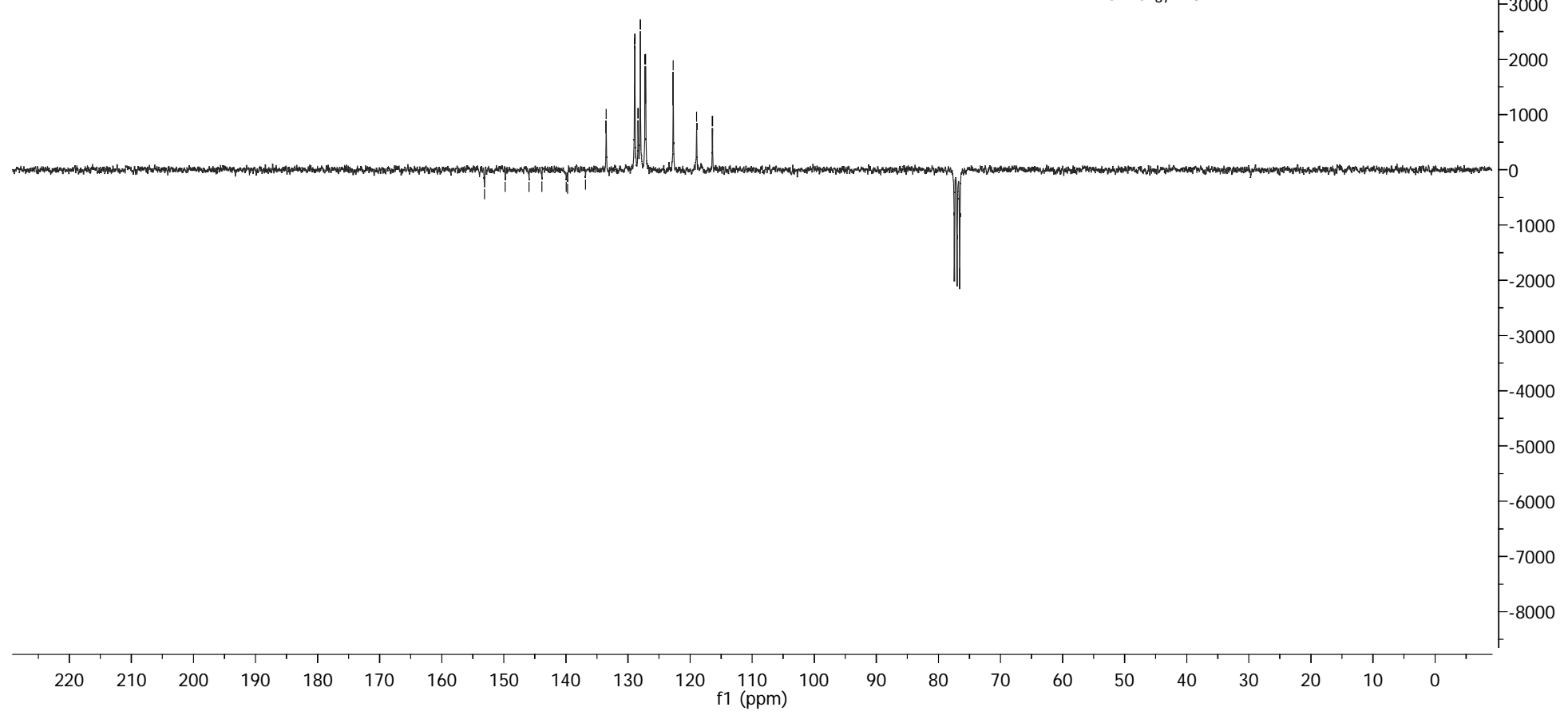

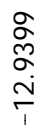

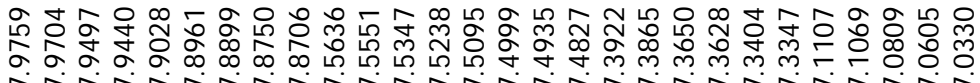

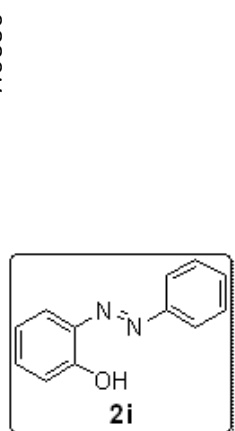



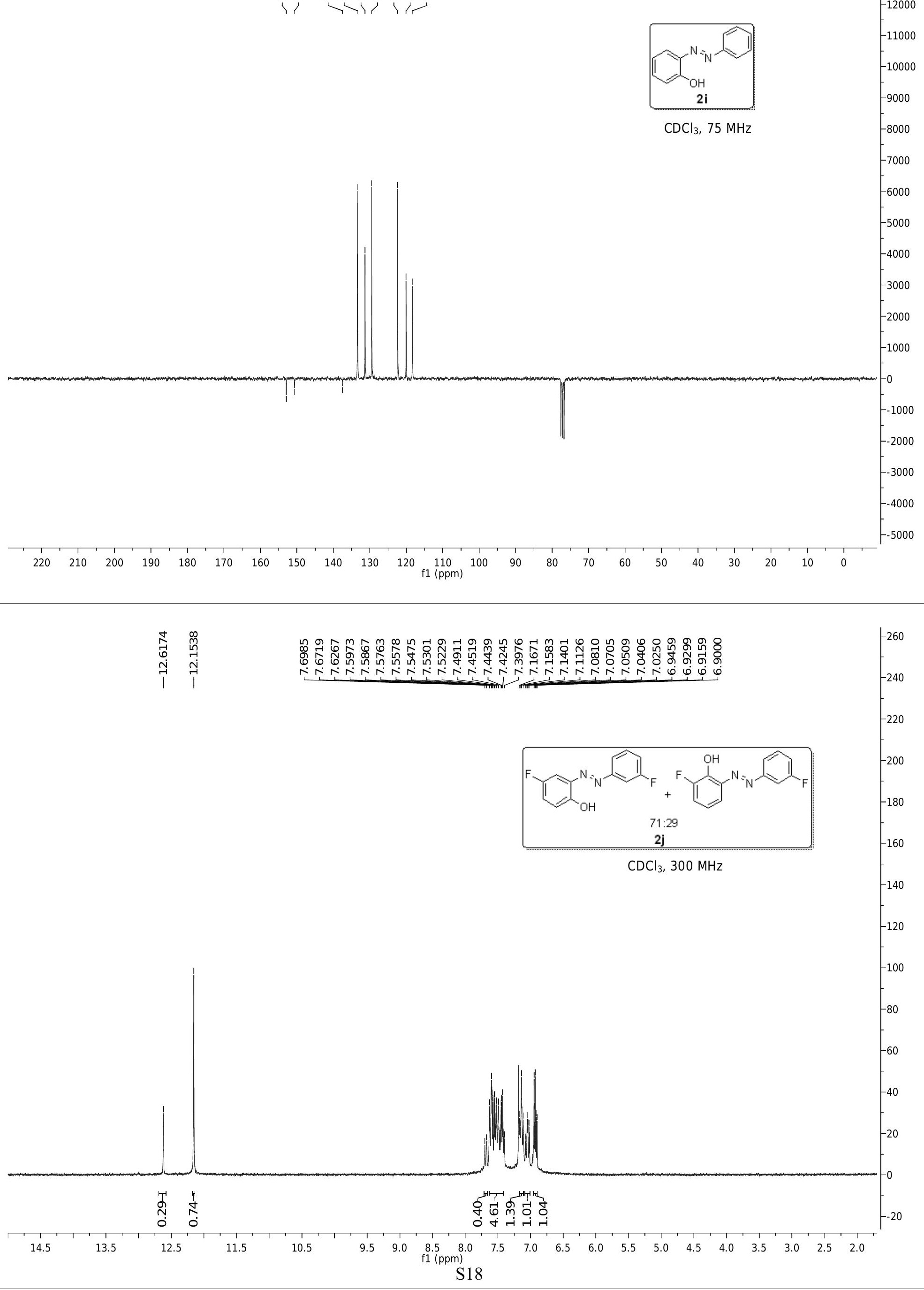


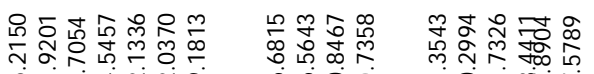

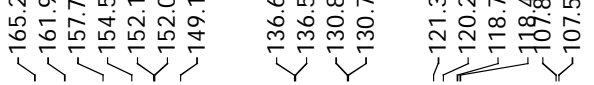

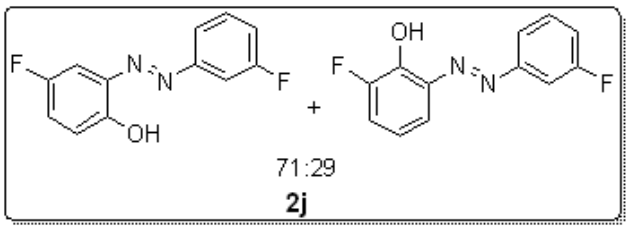

$2 \mathrm{j}$

$\mathrm{CDCl}_{3}, 75 \mathrm{MHz}$
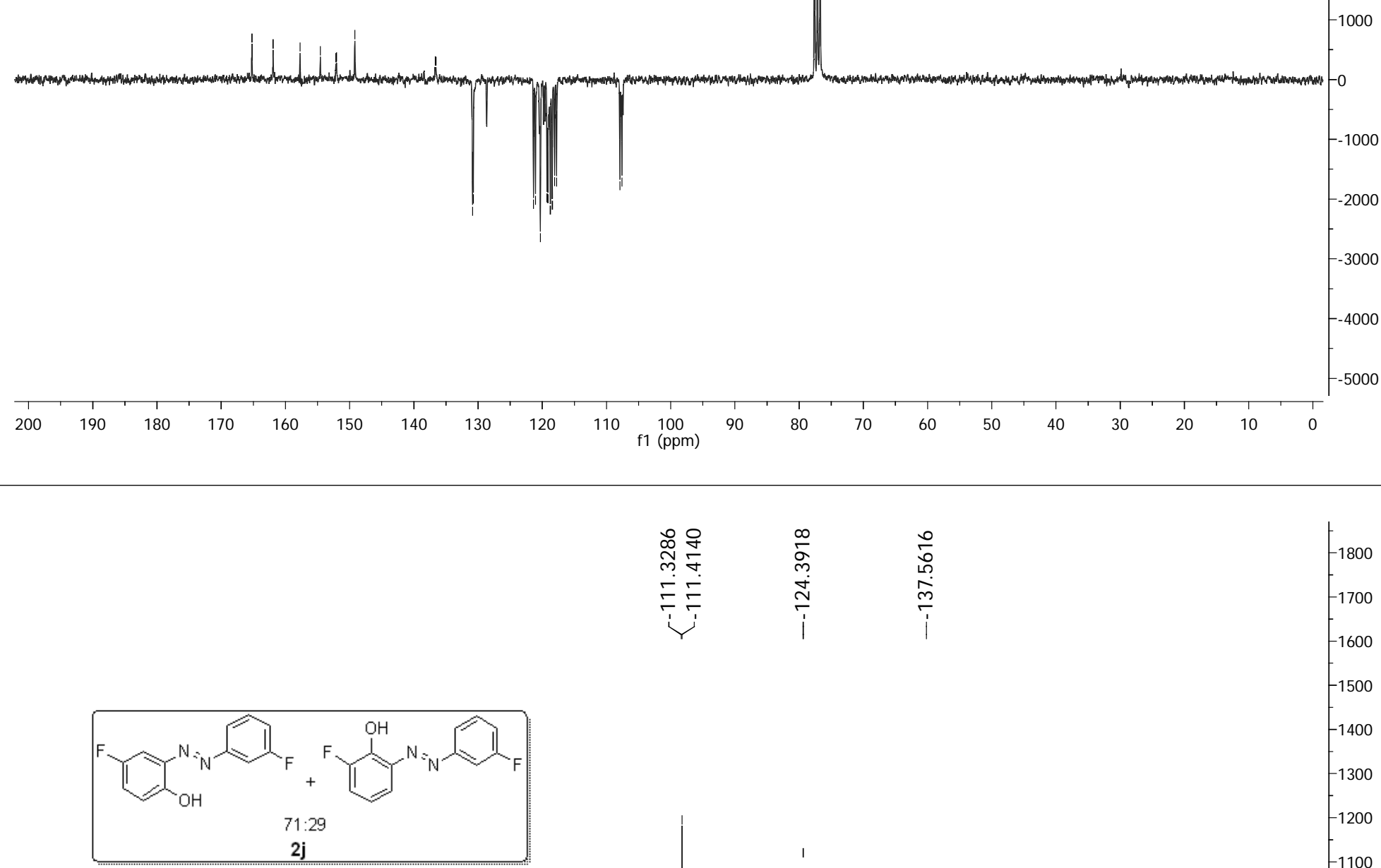

$\mathrm{CDCl}_{3}, 188 \mathrm{MHz}$

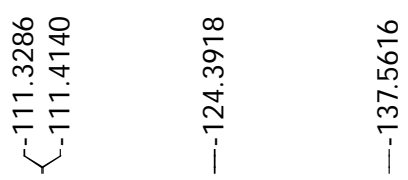

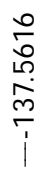




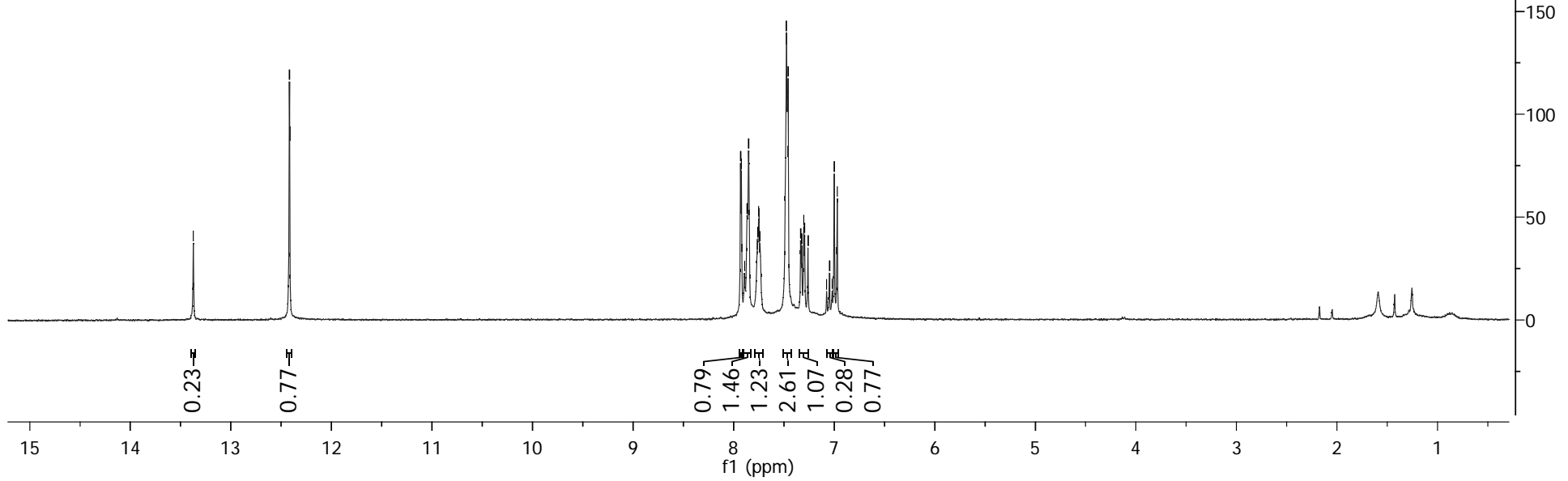

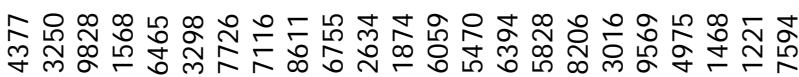

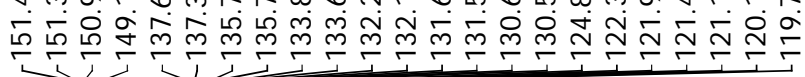

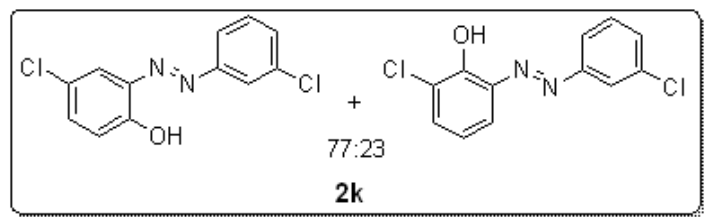

$\mathrm{CDCl}_{3}, 75 \mathrm{MHz}$

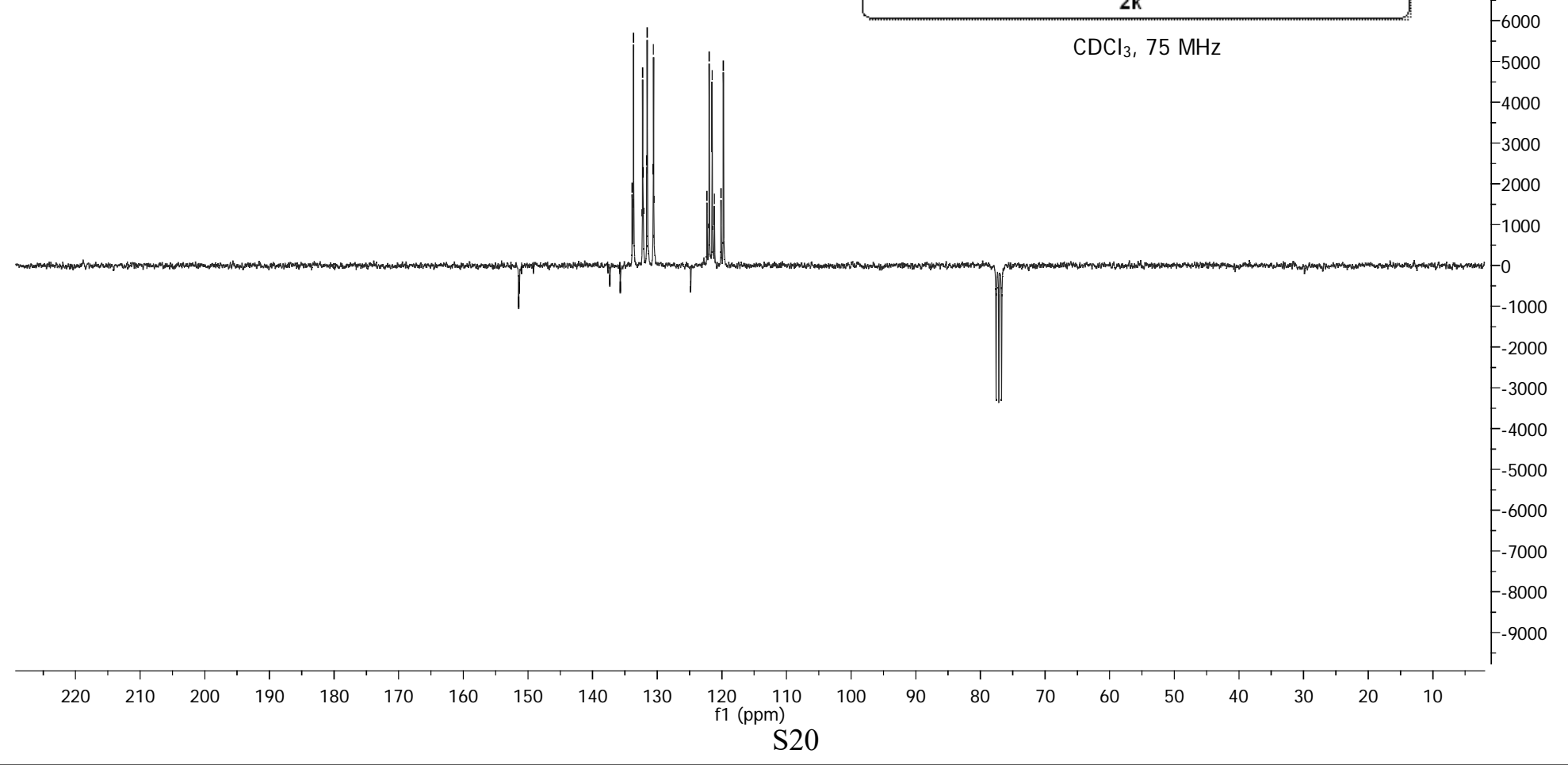



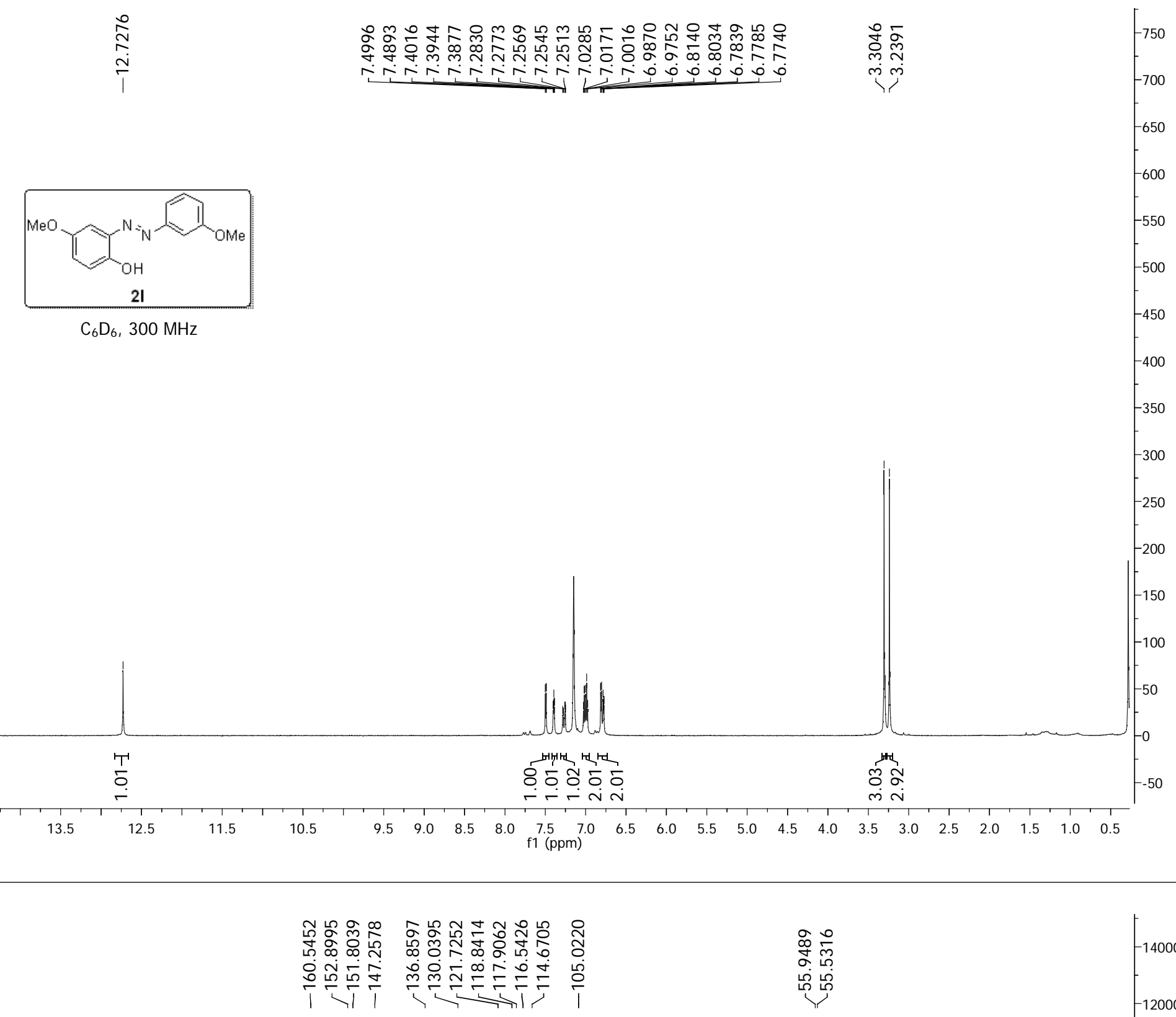

管兽

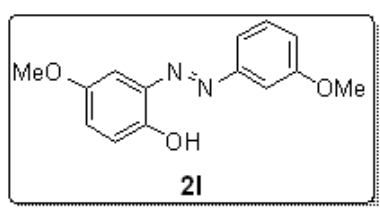

$\mathrm{CDCl}_{3}, 75 \mathrm{MHz}$

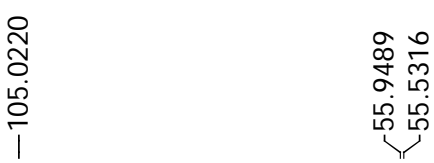




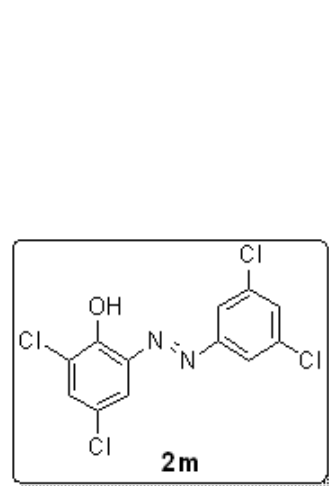

$\mathrm{CDCl}_{3}, 300 \mathrm{MHz}$

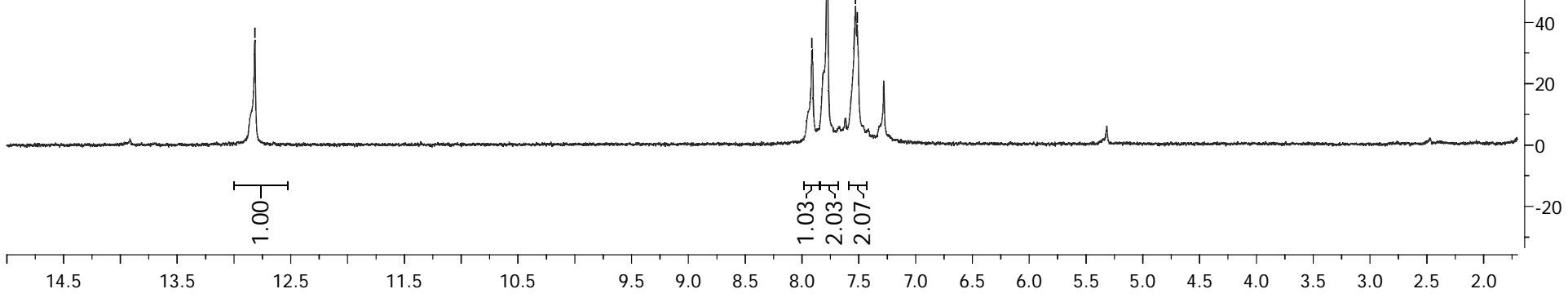

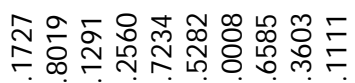

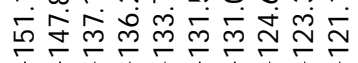

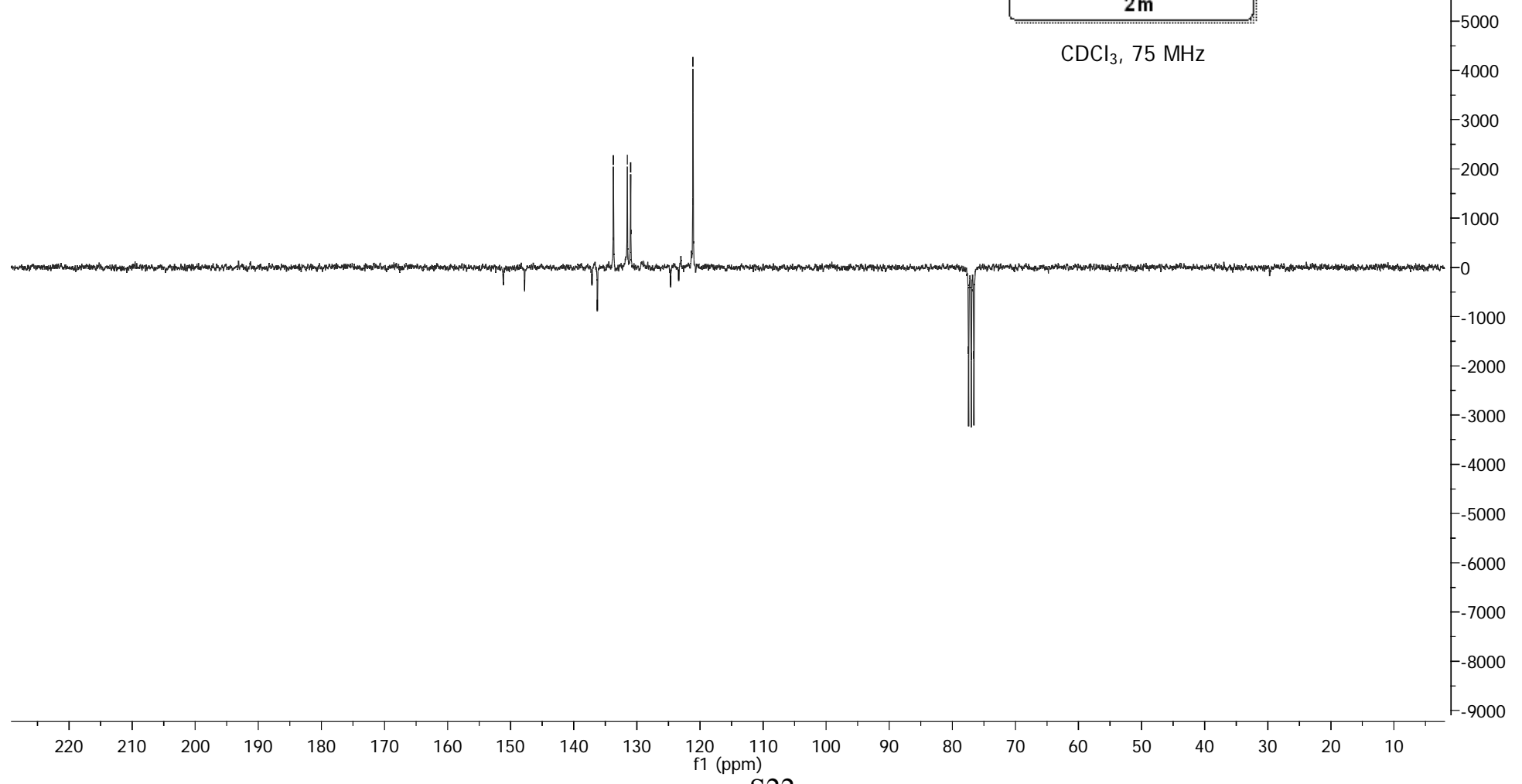

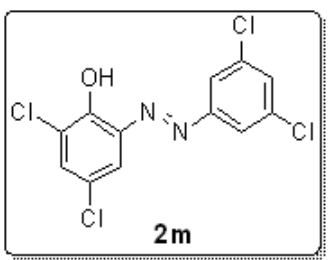

$\mathrm{CDCl}_{3}, 75 \mathrm{MHz}$ 


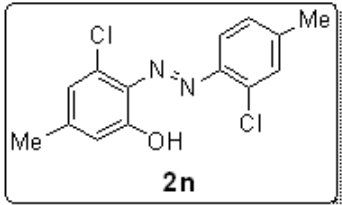

$\mathrm{CDCl}_{3}, 300 \mathrm{MHz}$
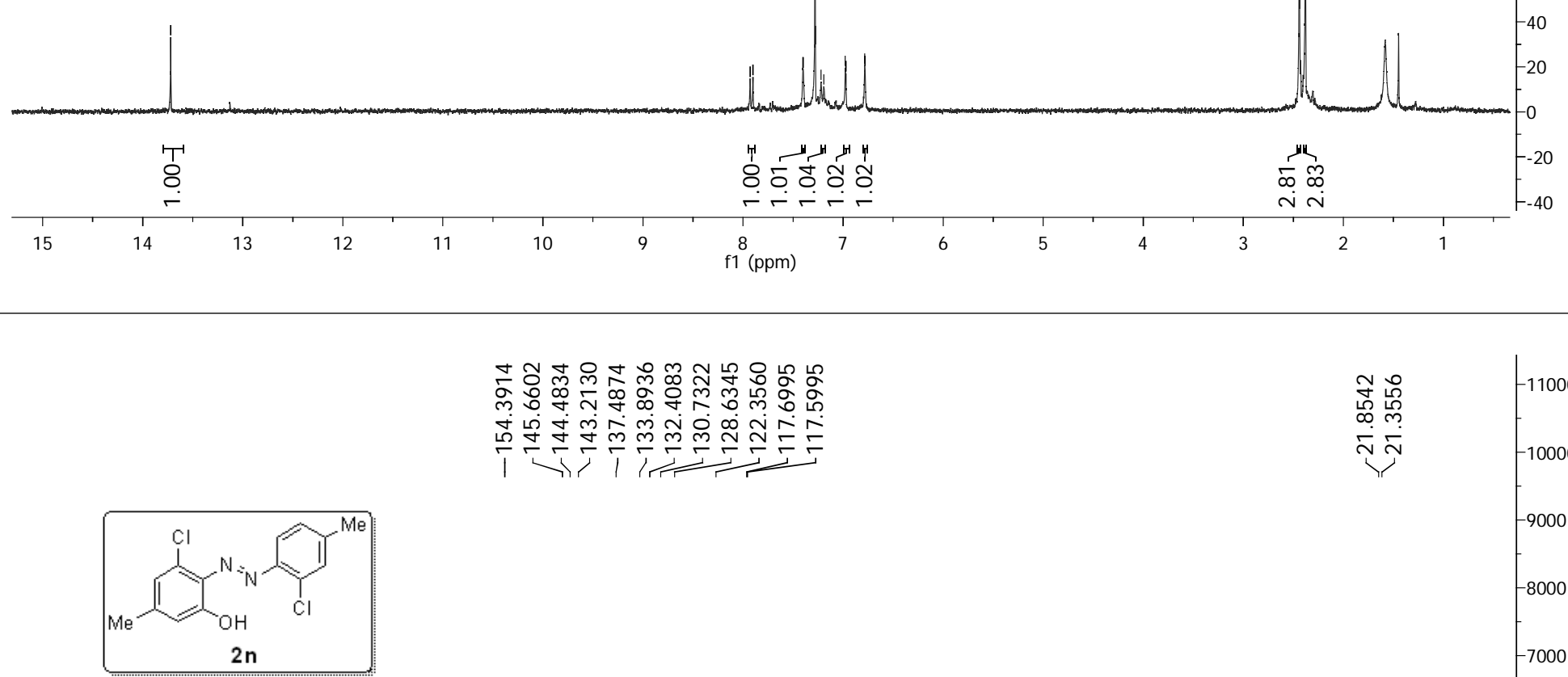

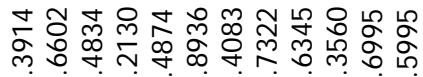

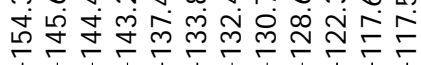

।

$\mathrm{CDCl}_{3}, 75 \mathrm{MHz}$

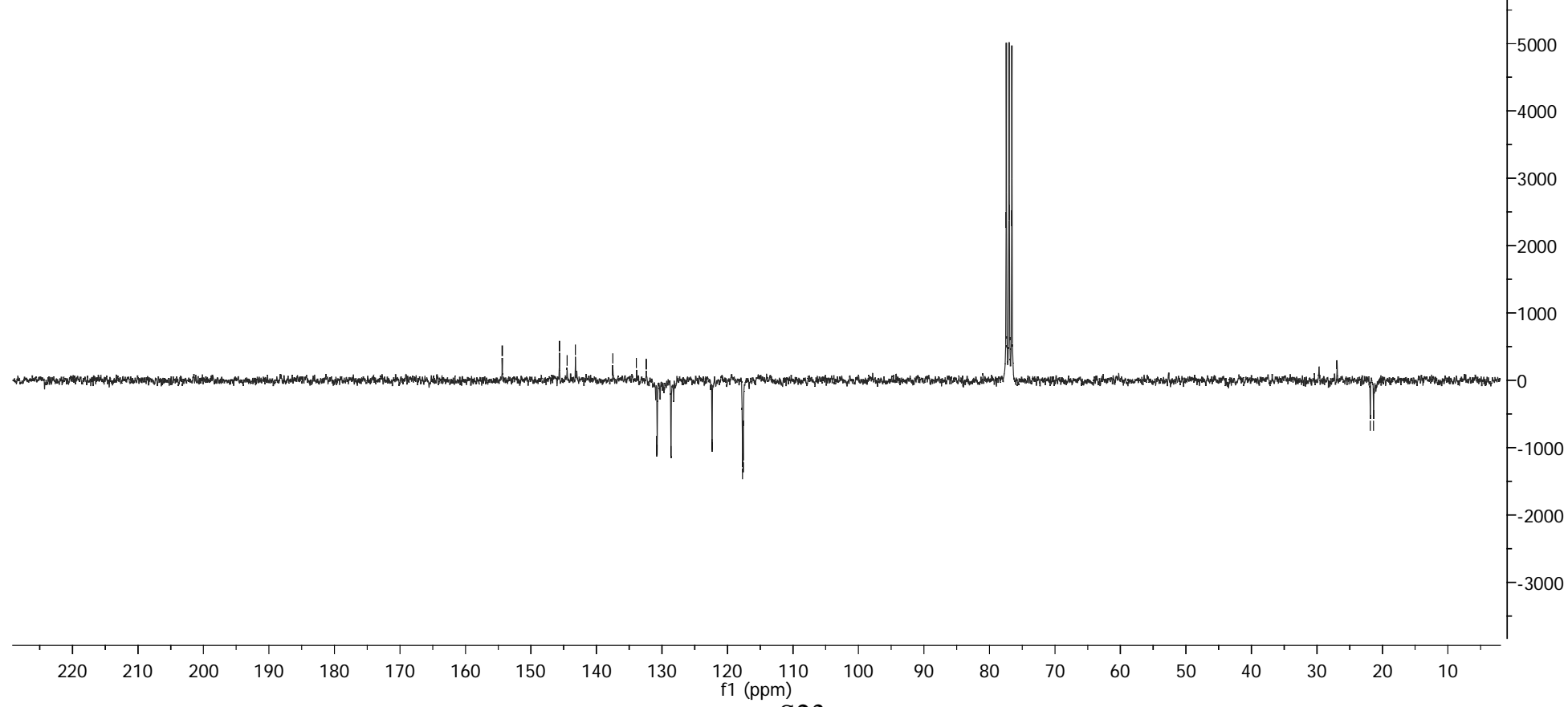


$\mathrm{COH}_{2 \mathrm{O}}^{\mathrm{Cl}}$

$\mathrm{CDCl}_{3}, 300 \mathrm{MHz}$

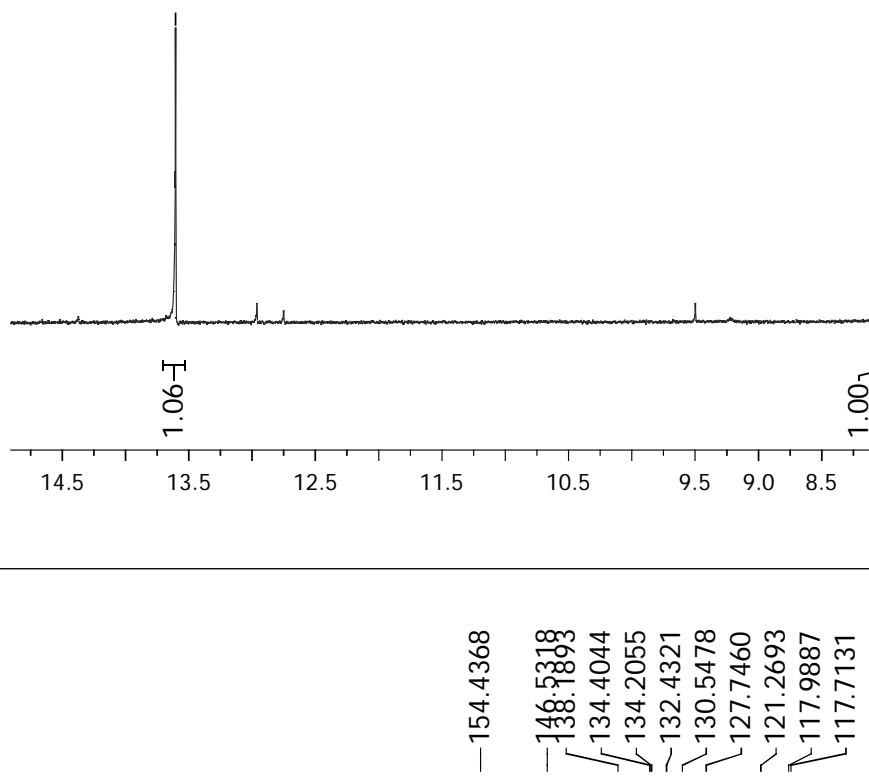

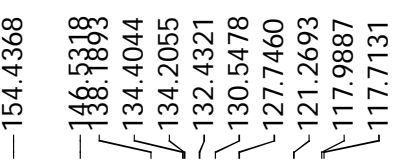




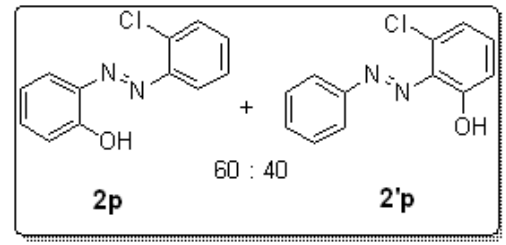

$\mathrm{CDCl}_{3}, 300 \mathrm{MHz}$

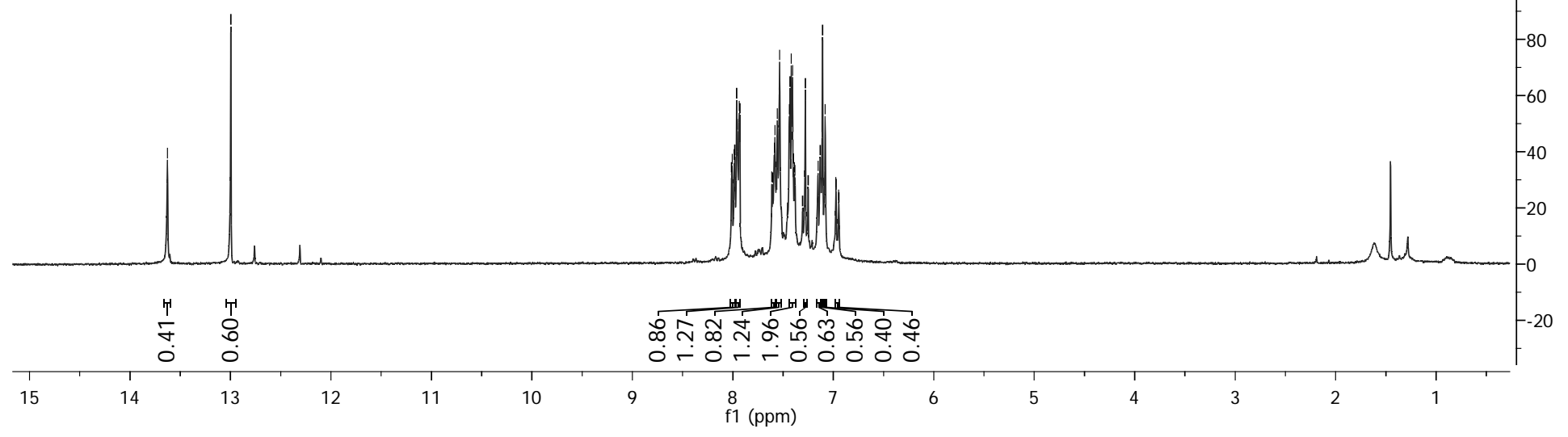

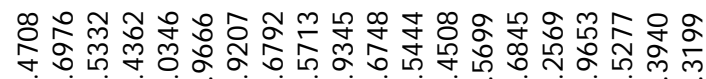

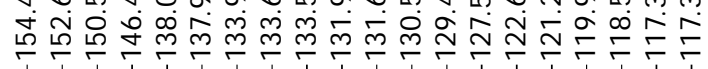

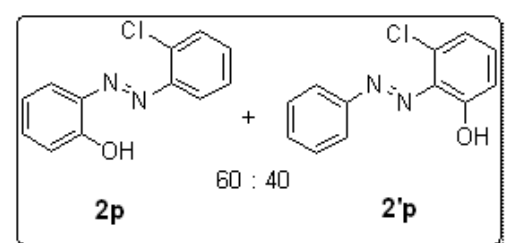




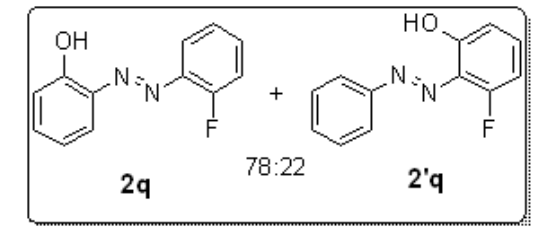

$\mathrm{CDCl}_{3}, 300 \mathrm{MHz}$

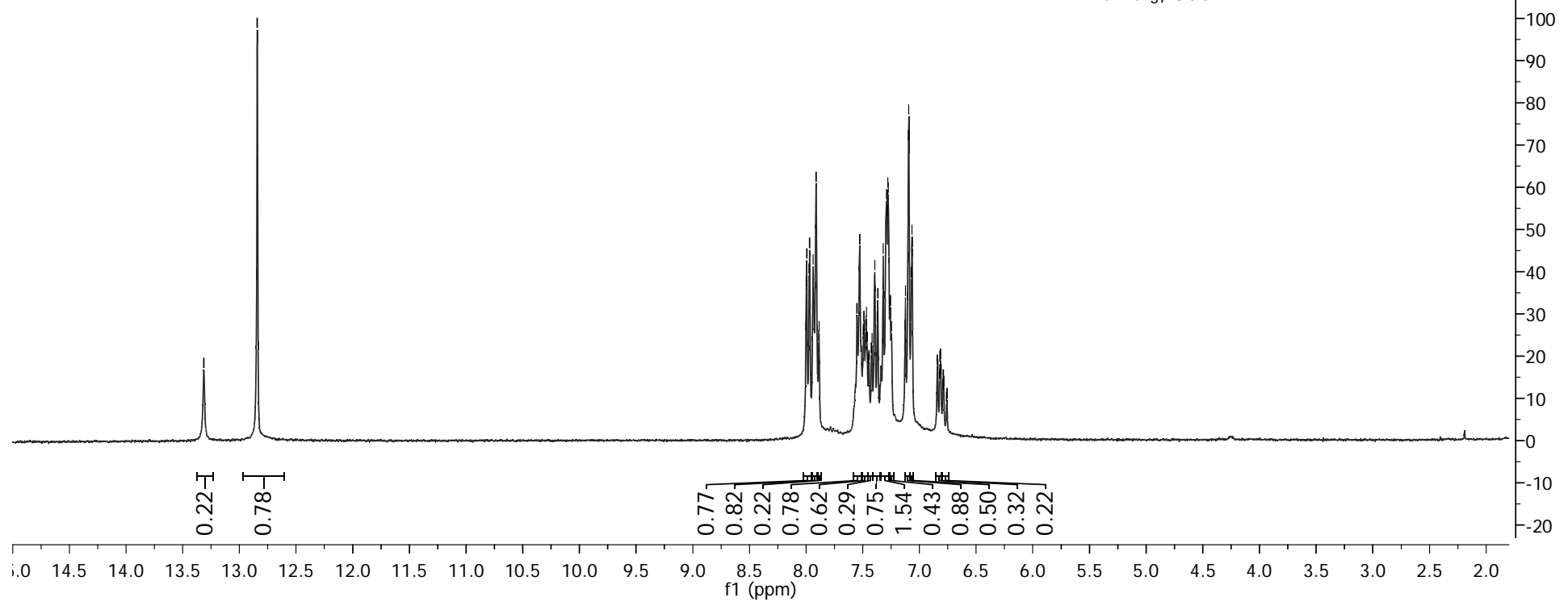

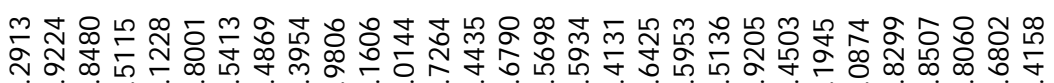

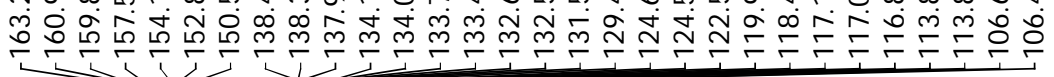

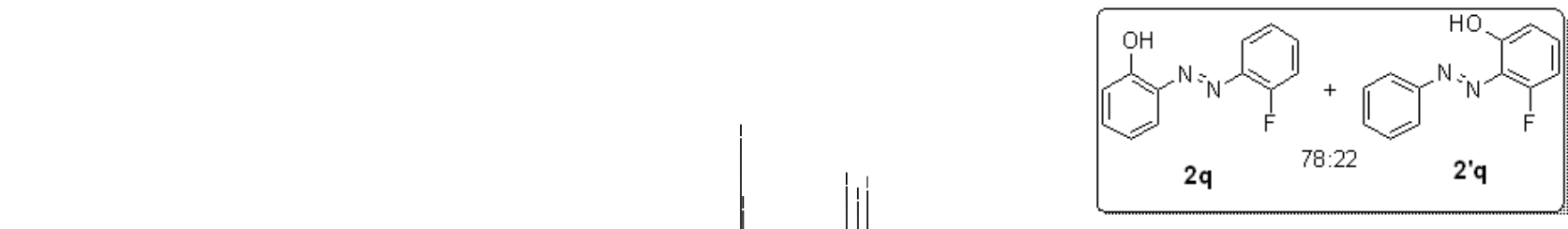


$\mathrm{CDCl}_{3}, 188 \mathrm{MHz}$

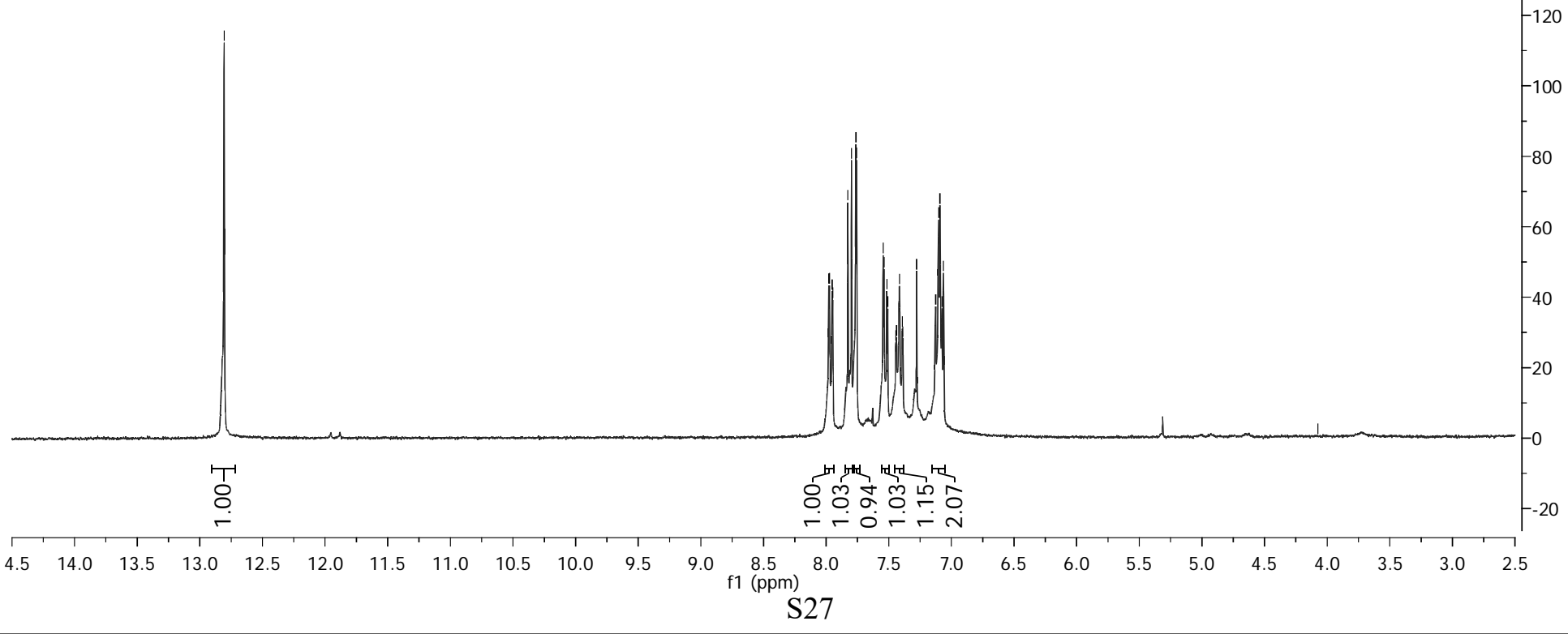




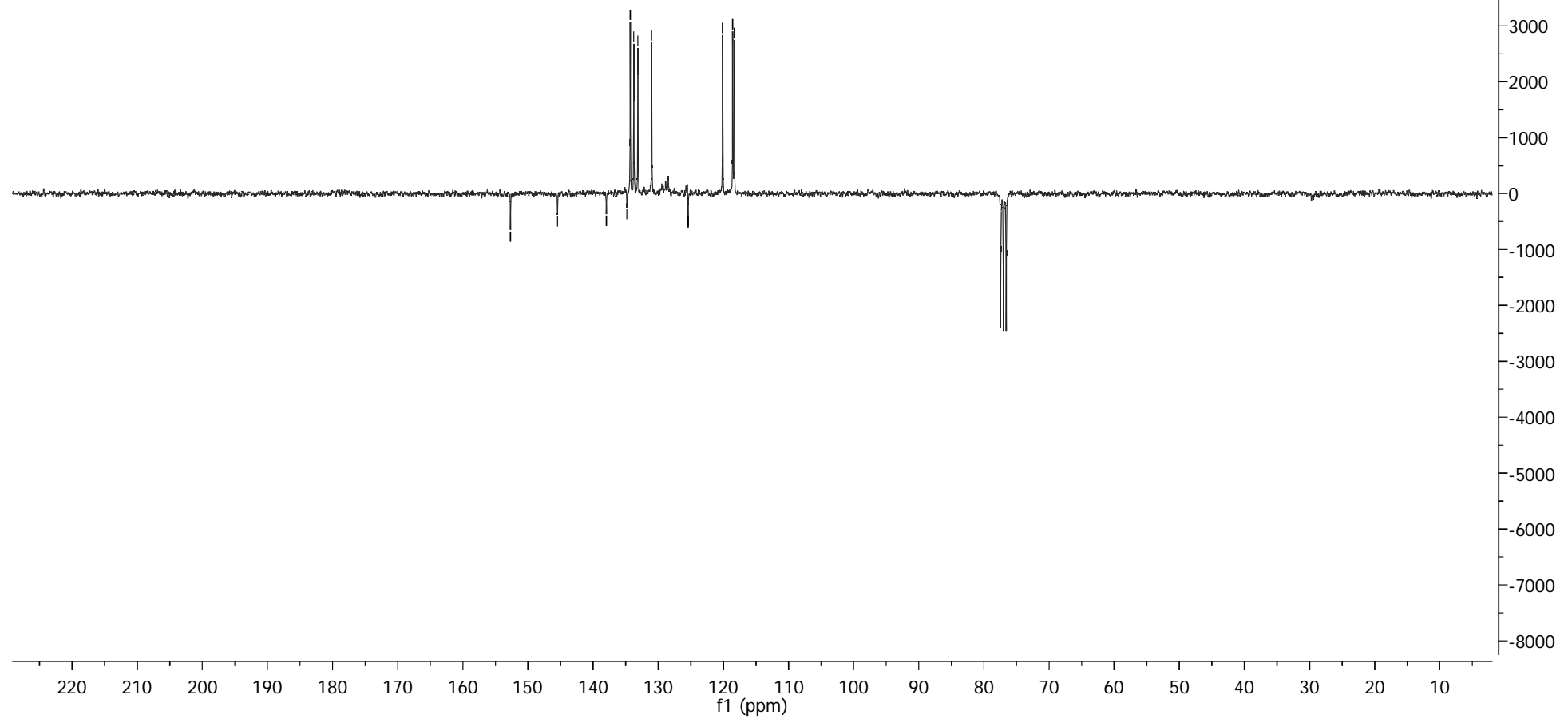

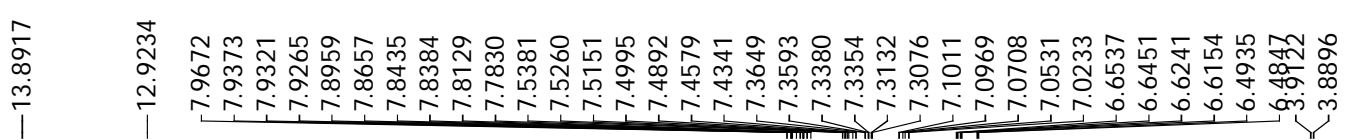
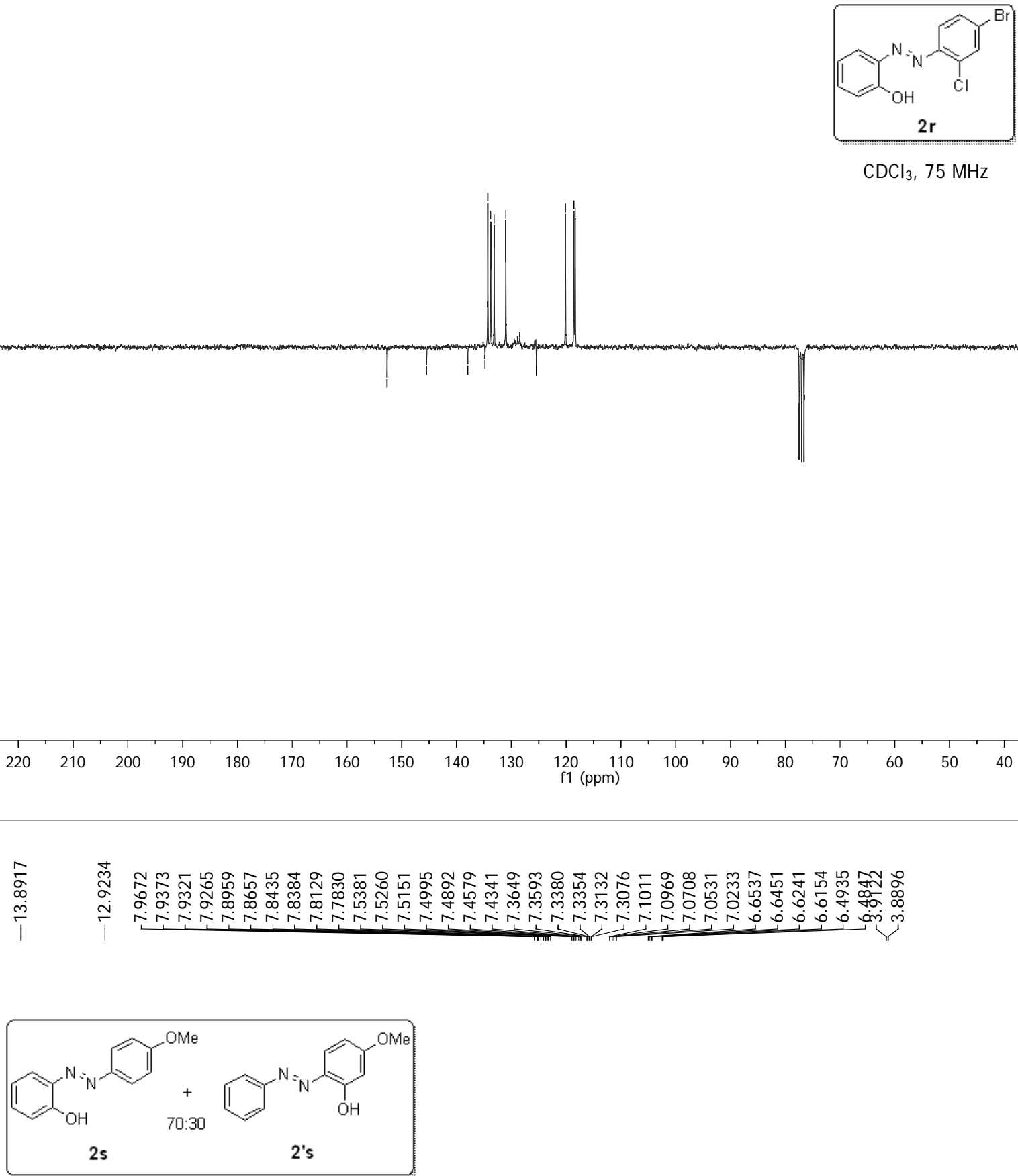

$\mathrm{CDCl}_{3}, 300 \mathrm{MHz}$

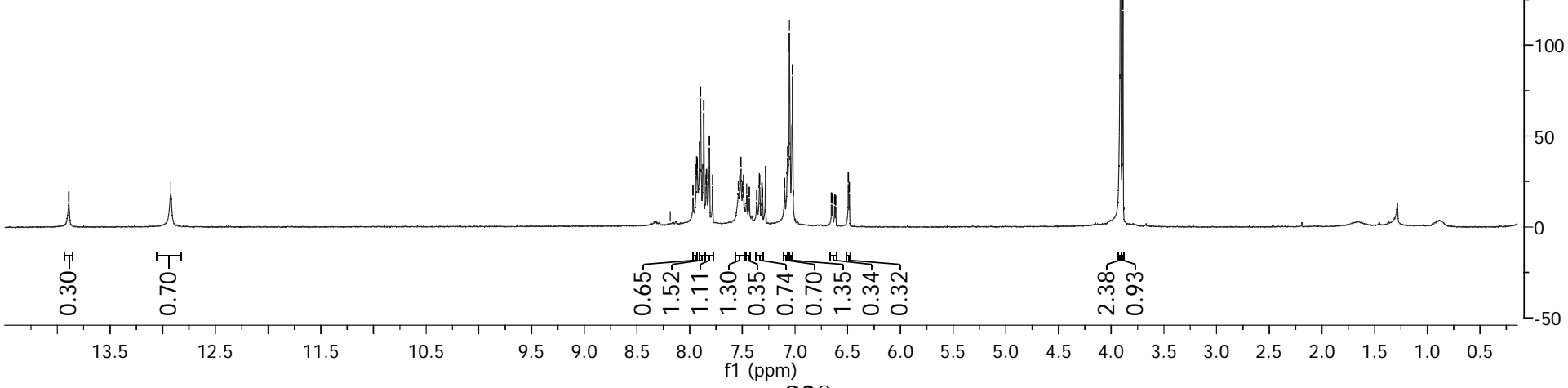




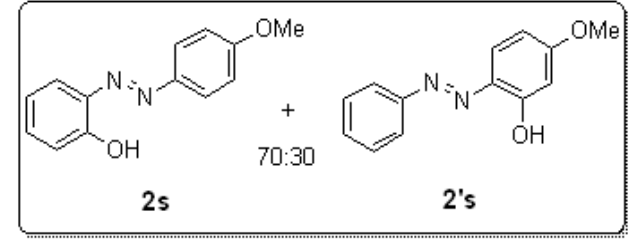

$\mathrm{CDCl}_{3}, 75 \mathrm{MHz}$

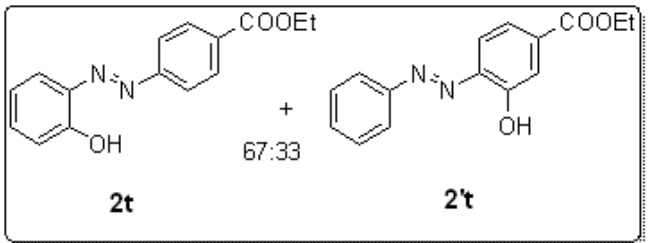

$\mathrm{CDCl}_{3}, 300 \mathrm{MHz}$

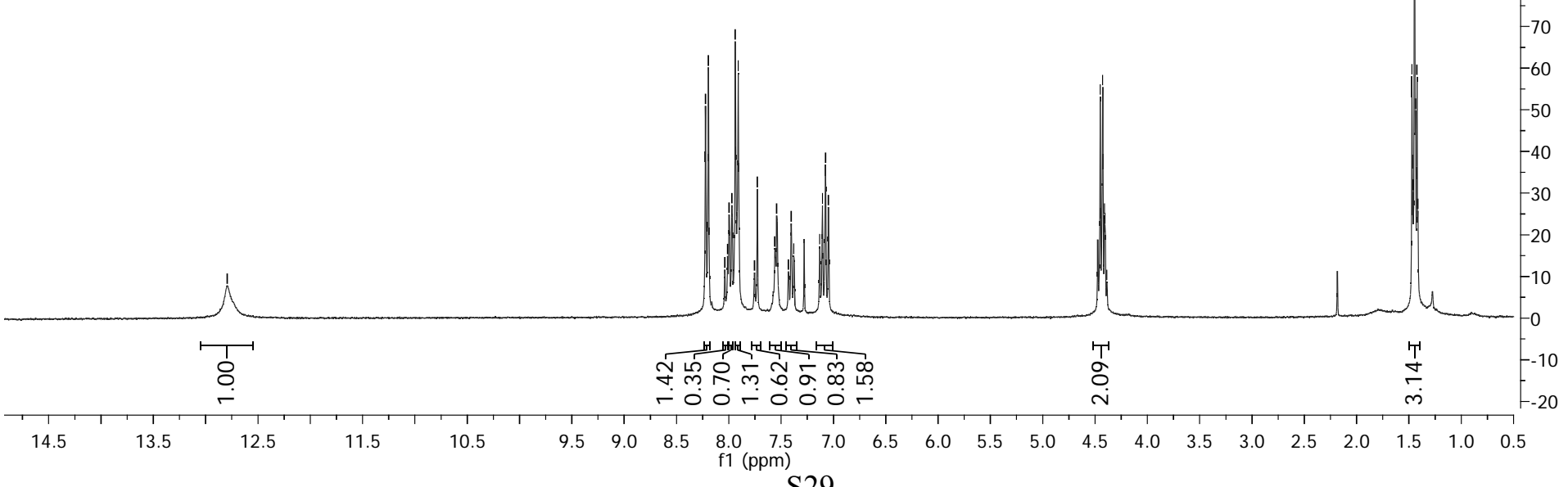




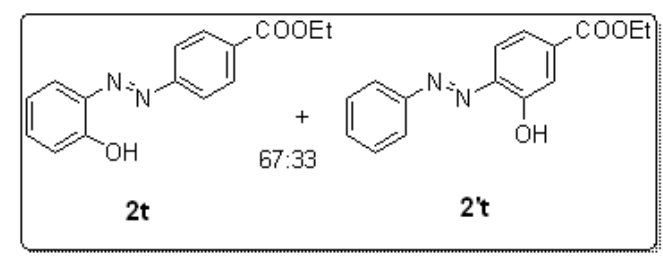

$\mathrm{CDCl}_{3}, 75 \mathrm{MHz}$

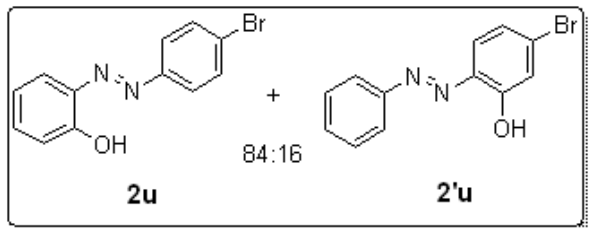

$\mathrm{CDCl}_{3}, 300 \mathrm{MHz}$

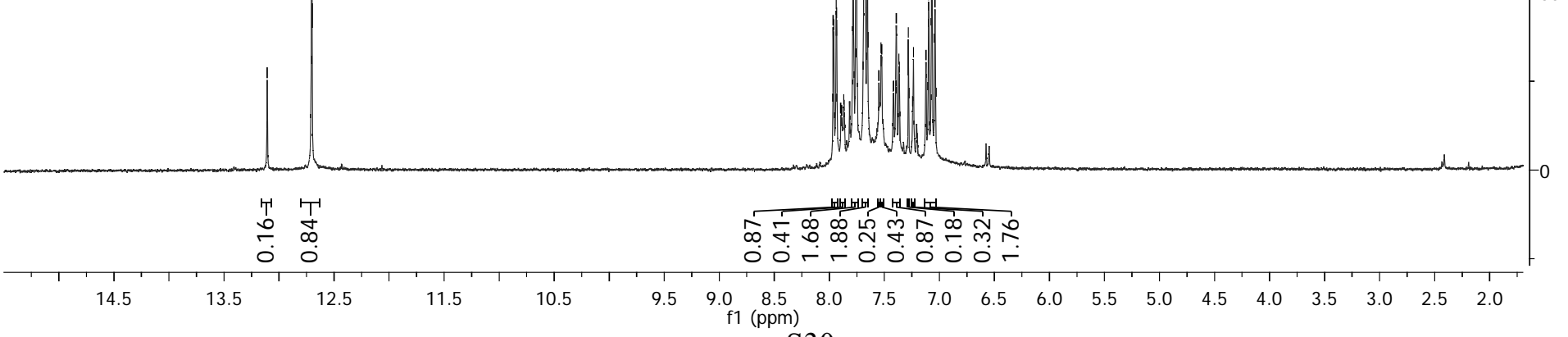




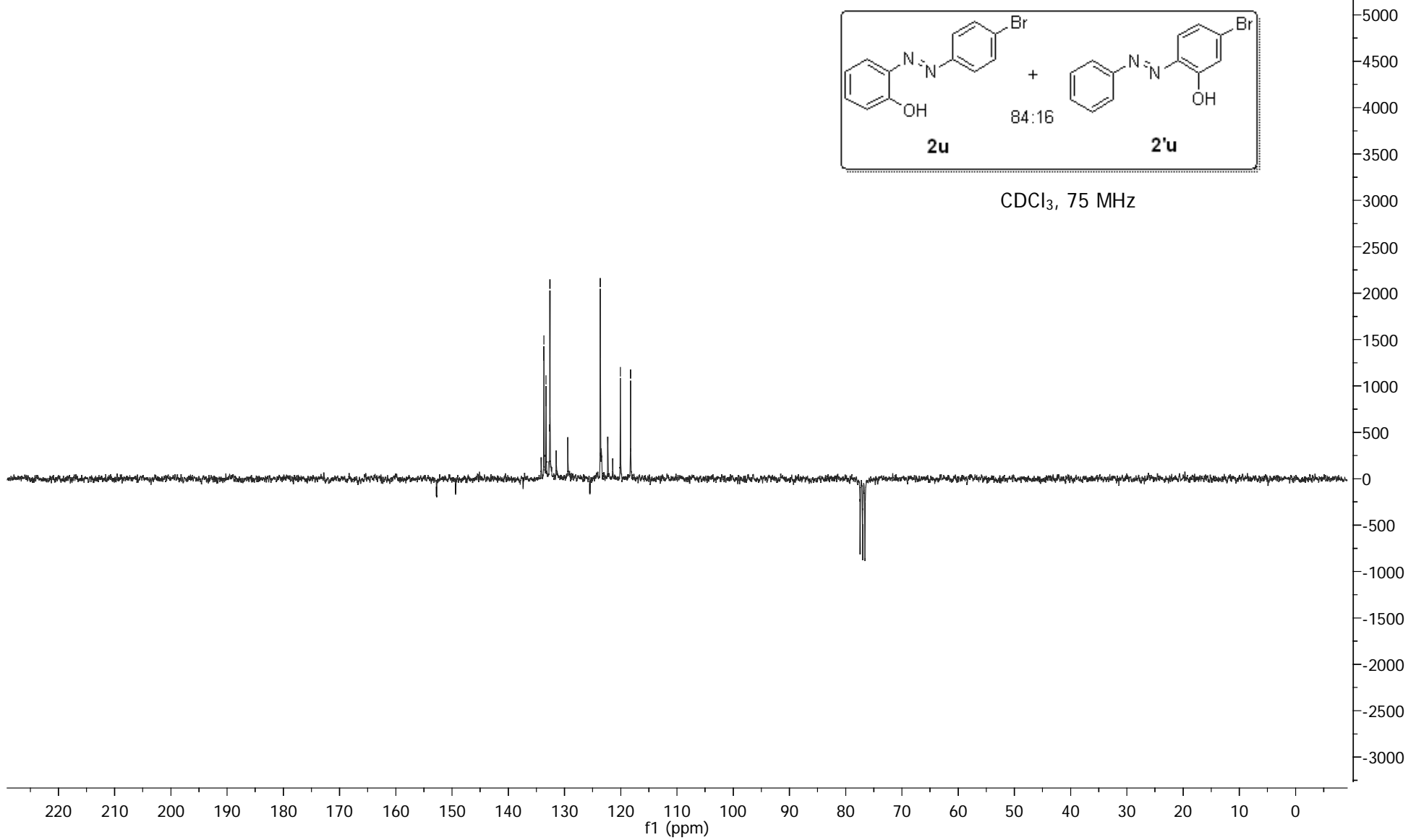

$\mathrm{CDCl}_{3}, 300 \mathrm{MHz}$

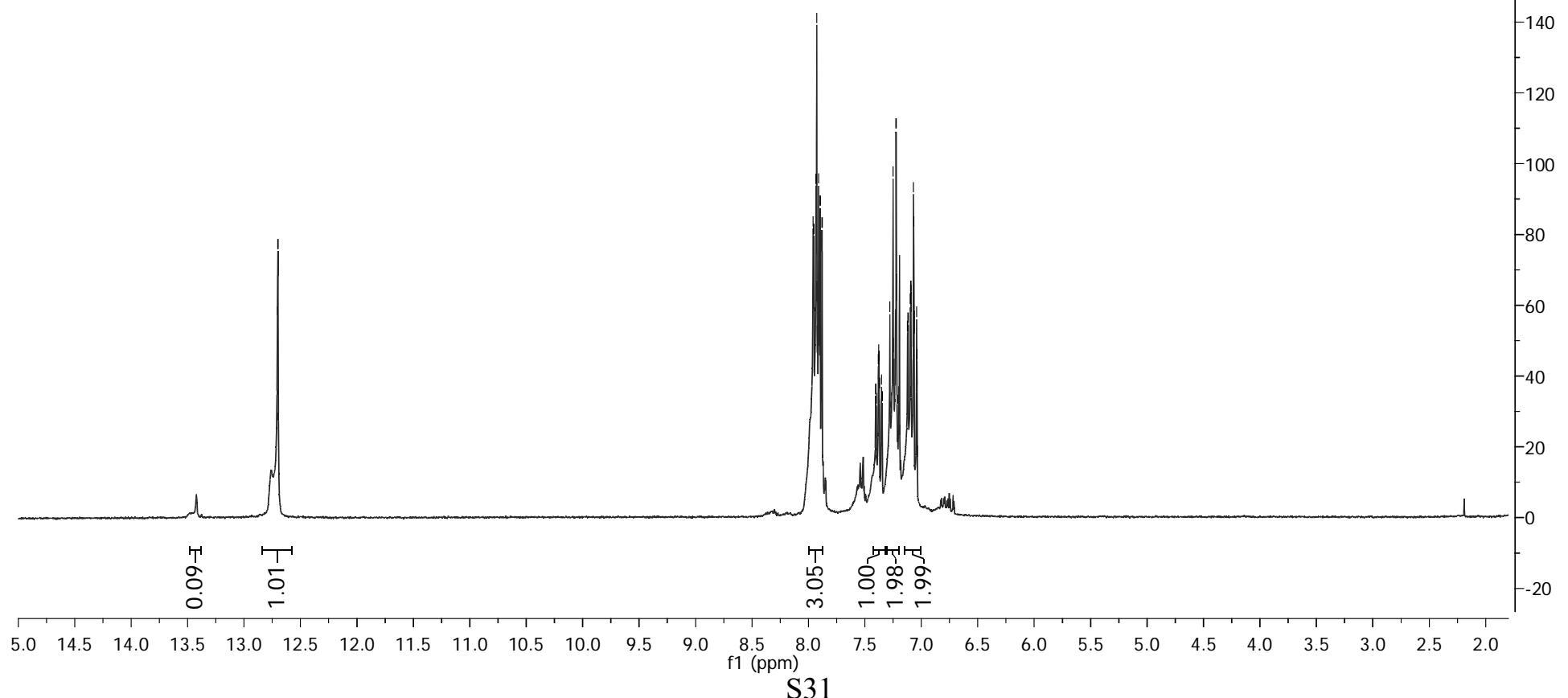




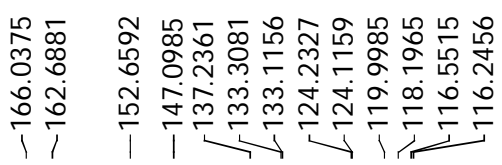

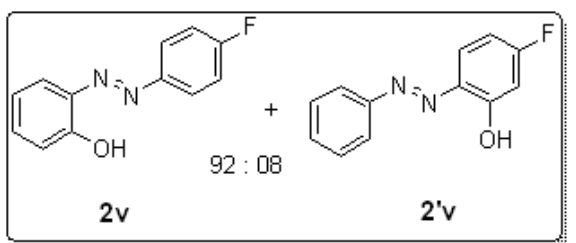

$\mathrm{CDCl}_{3}, 75 \mathrm{MHz}$

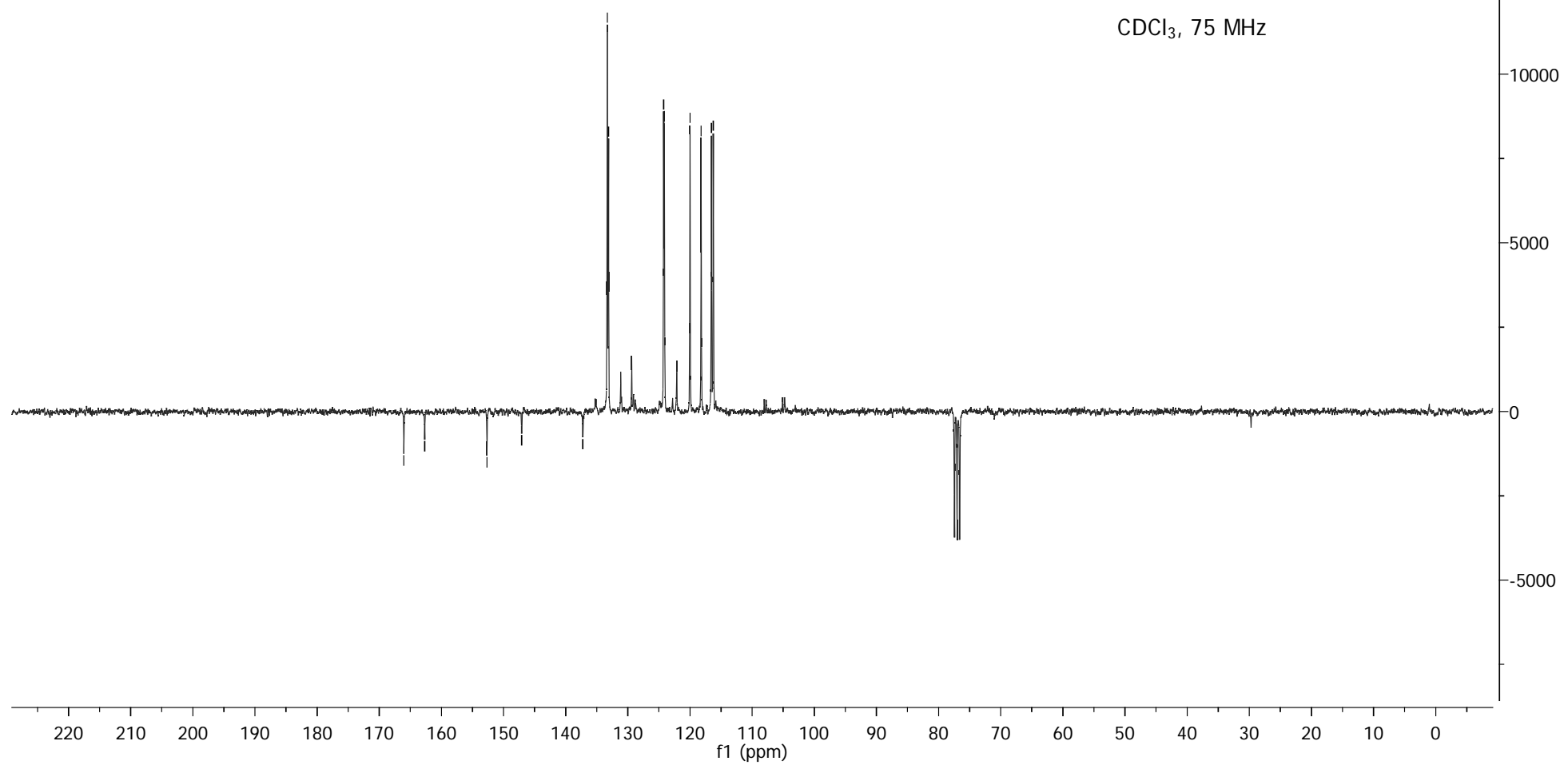

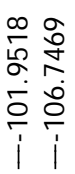

$-5500$

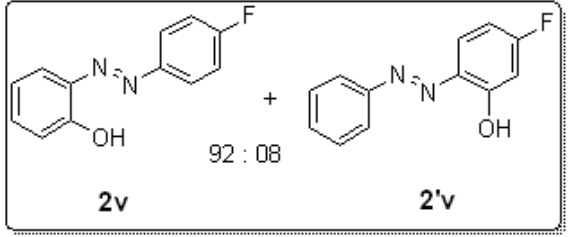

$\mathrm{CDCl}_{3}, 188 \mathrm{MHz}$ 


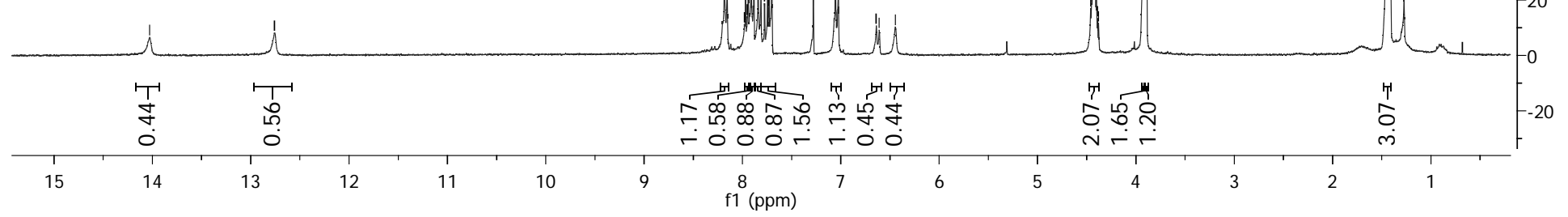

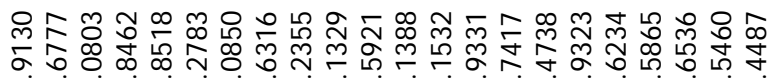

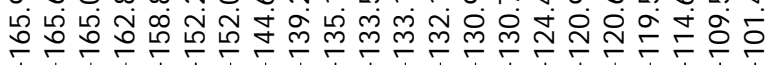

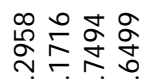

రิ่

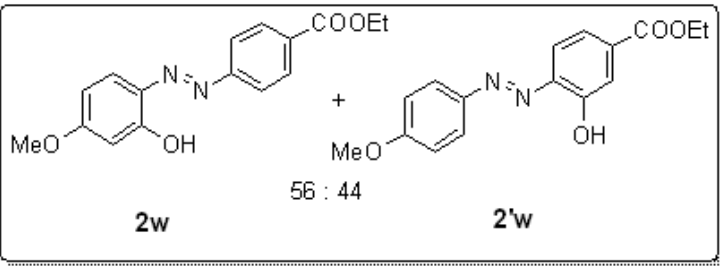

$\mathrm{CDCl}_{3}, 75 \mathrm{MHz}$

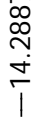

